NBER WORKING PAPER SERIES

\title{
DOES UNCERTAINTY REDUCE GROWTH? USING DISASTERS AS NATURAL EXPERIMENTS
}

\author{
Scott R. Baker \\ Nicholas Bloom \\ Working Paper 19475 \\ http://www.nber.org/papers/w19475 \\ NATIONAL BUREAU OF ECONOMIC RESEARCH \\ 1050 Massachusetts Avenue \\ Cambridge, MA 02138 \\ September 2013
}

We would like to thank the National Science Foundation and the Sloan Foundation for their financial support. We appreciated feedback from discussants Jonathan Goldberg, Ayhan Kose and Aart Kray, seminars participants at the AEA, the Chicago Fed, Maryland, IMF, Stanford, and the World Bank, and from Megha Patnaik and Stephen Terry. The views expressed herein are those of the authors and do not necessarily reflect the views of the National Bureau of Economic Research.

At least one co-author has disclosed a financial relationship of potential relevance for this research. Further information is available online at http://www.nber.org/papers/w19475.ack

NBER working papers are circulated for discussion and comment purposes. They have not been peerreviewed or been subject to the review by the NBER Board of Directors that accompanies official NBER publications.

(C) 2013 by Scott R. Baker and Nicholas Bloom. All rights reserved. Short sections of text, not to exceed two paragraphs, may be quoted without explicit permission provided that full credit, including @ notice, is given to the source. 
Does Uncertainty Reduce Growth? Using Disasters as Natural Experiments

Scott R. Baker and Nicholas Bloom

NBER Working Paper No. 19475

September 2013

JEL No. D92,E2,O4

\begin{abstract}
$\underline{\text { ABSTRACT }}$
A growing body of evidence suggests that uncertainty is counter cyclical, rising sharply in recessions and falling in booms. But what is the causal relationship between uncertainty and growth? To identify this we construct cross country panel data on stock market levels and volatility as proxies for the first and second moments of business conditions. We then use natural disasters, terrorist attacks and unexpected political shocks as instruments for our stock market proxies of first and second moment shocks. We find that both the first and second moments are highly significant in explaining GDP growth, with second moment shocks accounting for at least a half of the variation in growth. Variations in higher moments of stock market returns appear to have little impact on growth.
\end{abstract}

Scott R. Baker

Stanford University

Department of Economics

579 Serra Mall

Stanford, CA 94305

srbaker@stanford.edu

Nicholas Bloom

Stanford University

Department of Economics

579 Serra Mall

Stanford, CA 94305-6072

and NBER

nbloom@stanford.edu 


\section{Introduction}

A rapidly growing literature is centered on investigating the relationship between uncertainty and growth. One emerging fact from this literature is that macro and micro uncertainty is counter cyclical, rising steeply in recessions and falling in booms. ${ }^{1}$ For example, Figure 1 plots five different proxies for uncertainty - macro and micro stock volatility, exchange rate volatility, bond yield volatility and GDP forecast disagreement against GDP growth quintiles for 60 countries from 1970 to 2012. There is a clear downward relationship between uncertainty and GDP growth, which is robust to splits by country (e.g. developed and developing) and time period (e.g. pre and post 2000).

What is not clear, however, is to what extent this relationship is casual. Does uncertainty drive recessions, do recessions drive uncertainty, or does something else drive both? Since theoretical models of uncertainty and economic activity predict effects in both directions $^{2}$, identifying the direction of causation is ultimately an empirical question.

Identifying the direction of this relationship is difficult because most macro variables move together over the business cycle, without any obvious causal direction. In large part this is because, as Kocherlakota (2009) aptly noted, "The difficulty in macroeconomics is that virtually every variable is endogenous". As a result, the prior literature has either assumed the direction of causation, or relied on timing for identification in estimators like a Vector Auto Regression. This is problematic, however, because of the contemporaneous movement of macro variables and the forward looking nature of investment and hiring. Because of this, it is not surprising that a wide range of results have been found using VAR regressions because of their sensitivity to subtle differences in auxiliary assumptions. ${ }^{3}$

\footnotetext{
${ }^{1}$ See, for example, evidence of counter-cyclical volatility in: macro stock returns in the US in Schwert (1989), in firm-level stock returns in Campbell et al. (2001), Bloom, Bond and Van Reenen (2007) and Gilchrist et al (2009); in plant, firm, industry and aggregate output and productivity in Bloom, Floetotto, Jaimovich, Saporta and Terry (2011), Kehrig (2010) and Bachman and Bayer (2011); in price changes in Berger and Vavra (2010); and in consumption and income in Storesletten et al (2004), Meghir and Pistaferri (2004) and Guvenen, Ozkan and Song (2013). Other papers find that GDP and prices forecasts have a higher within-forecaster dispersion and cross-forecaster disagreement in recessions, for example, Bachman et al (2010), Popescu and Smets (2009) and Arslan et al (2011); that the frequency of the word "uncertainty" close to the word "economy" rises steeply in recessions (e.g. Alexopoulos and Cohen (2011)), and a broad uncertainty factor indicator is counter-cyclical (Jurado, Ludvigson and Ng, 2013).

${ }^{2}$ Models predicting impacts of uncertainty on economic activity include effects via: (a) risk aversion; (b) via the concavity of the production function (for example Oi (1961), Hartman (1976) and Abel (1983)); (c) real-options effects (for example Bernanke (1983), Bertola and Caballero (1994), Dixit and Pindyck (1996), Hassler (1996), Gilchrist and Williams (2005), Sim (2008)); and (d) via financial contracting frictions (for example, Arrellano et al. (2010), and Narita (2011)). There are also models predicting effects of economic activity on uncertainty, for example on information collection in Van Nieuwerburgh and Veldkamp (2006) and Fajgelbaum et al. (2012), on noise-trading in Albagli (2011), on R\&D in D’Erasmo and Moscoso Boedo (2011), on experimentation in Bachman and Moscarini (2011) and on policy in Bianchi and Melosi (2012).

${ }^{3}$ For example, Bloom (2009), Christiano et al. (2010), Arslan et al. (2011), Fernandez-Villaverde (2011) and Alexopoulos and Cohen (2011) report a large impact of uncertainty on recessions in their VARs, while
} 


\section{Figure 1: All our uncertainty proxies are negatively correlated with growth across our (unbalanced) panel for 60 countries, 1970-2012}

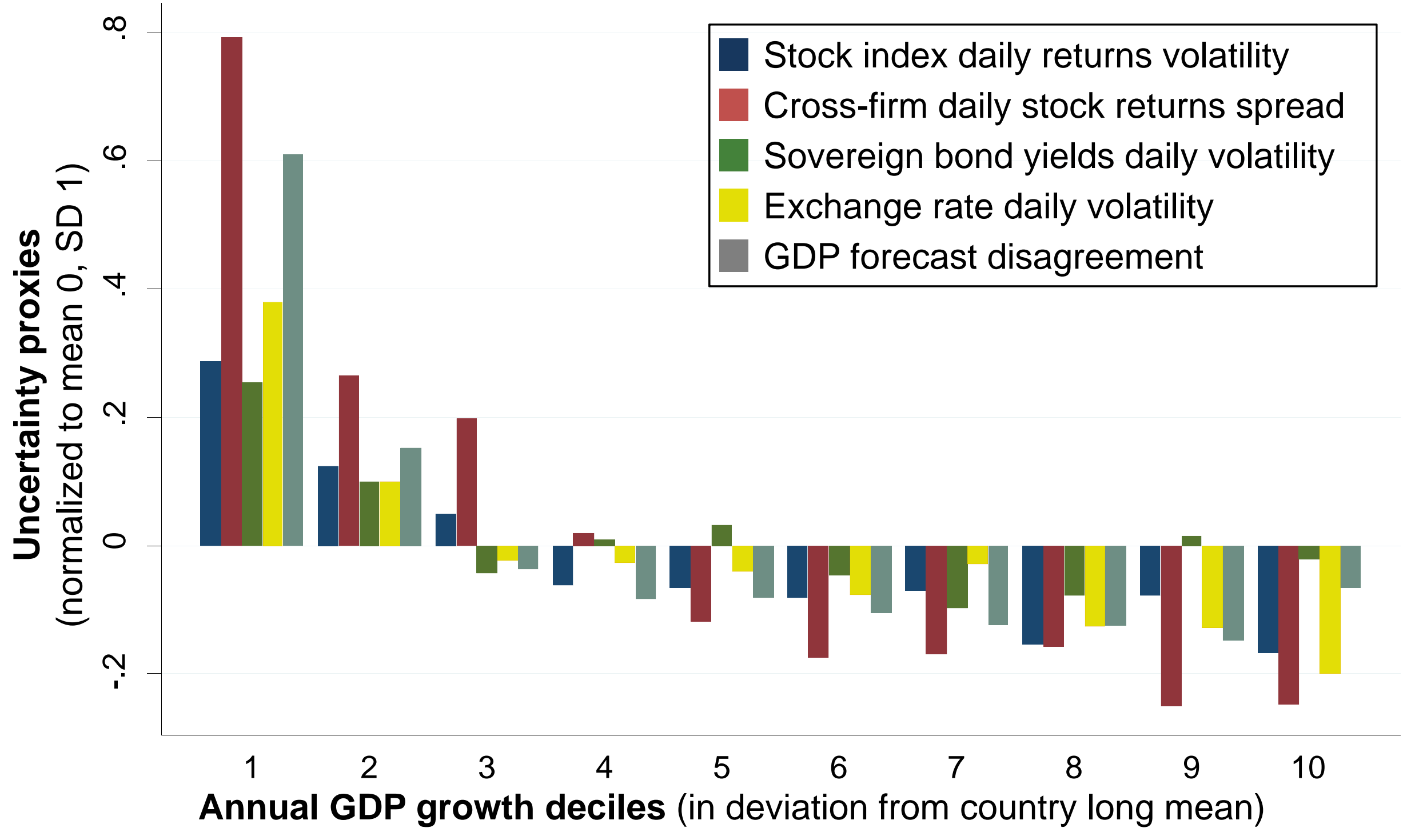

Notes: Volatility indicators constructed from the unbalanced panel of daily data from 1970 to 2012 from 60 countries. Volatility values are calculated across all trading days (1-year ahead GDP growth forecasts) within each year, and then normalized for presentational purposes so each of the five indicators has a mean of 0 and a standard-deviation of 1 over the sample. The GDP growth deciles are calculated using annual values in deviations from the country mean across the sample. 
In this paper we take what we believe is a more robust approach, which exploits the large number of exogenous shocks that occur in a quarterly panel of sixty countries since 1970 . These exogenous shocks are natural disasters, terrorist attacks, political coups and revolutions. We use these shocks to instrument for changes in the level and volatility of stock-market returns as a way to separate the effects of our exogenous shocks into first and second-moment components. The identifying assumption is that some shocks - like natural disasters - lead primarily to a change in stock-market levels and are more first moment shocks, while other shocks like coups lead more to changes in stock-market volatility, implying they are more of a second moment shock.

To refine this analysis, we weight each event by the increase in Google News daily article counts of the affected country in the fifteen days after the event compared to the fifteen days before the event. For example, we would use the 322\% increase in the count of the word "Japan" in fifteen days after the March $11^{\text {th }} 2011$ earthquake compared to the fifteen days before to weight this shock. This ensures that only events that are unanticipated are included, since anticipated events like elections and major sports events do not generate jumps in coverage on the day they occur. Moreover the largest most newsworthy shocks will get the largest weight, which should be correlated with their economic impact.

To highlight how our identification strategy focuses on surprise events Figure 2 shows the average increase in newspaper coverage of the countries in which the shocks occurred for fifteen days before and after they occurred. This shows these events lead to a jump in newspaper coverage on the day of the event, and an increase of 39\% over the fifteen days after the event. For comparison Figure 3 shows the media coverage around general elections, showing no jump in the days after compared to the days before the event. ${ }^{4}$

Using this strategy of weighting events by their increase in media coverage, we find a significant causal impact of both first and second moment effects on economic activity. In the quarter following a shock, we estimate a one standard deviation reduction in stockmarket levels (our first moment proxy) and a one standard deviation increase in stockmarket volatility (our second moment proxy) leads to a $1.61 \%$ and $1.64 \%$ respective reduction in GDP growth. In the year following a shock we estimate larger effects (from less measurement error induced attenuation bias), with a one standard deviation reduction in stock market levels and rise in stock market volatility leading to falls in annual GDP growth of $2.20 \%$ and $7.11 \%$ respectively. Hence, first and second moment effects are both significant drivers of growth, with second moment effects having equal or higher impact.

There are clearly some potential issues with this identification strategy. One of these is whether stock market volatility is a good indicator of second moment shocks to business

Bachman and Bayer (2010) and Bachman et al. (2011) report the reverse (a large effect of recessions on uncertainty).

${ }^{4}$ We also did similar analysis for other predictable but media-important events like the World Cup and Super Bowl, also finding no jump in coverage around the event. 
Figure 2: Newspaper daily word counts for the affected country in the one month around the natural disaster, political or terrorist shock

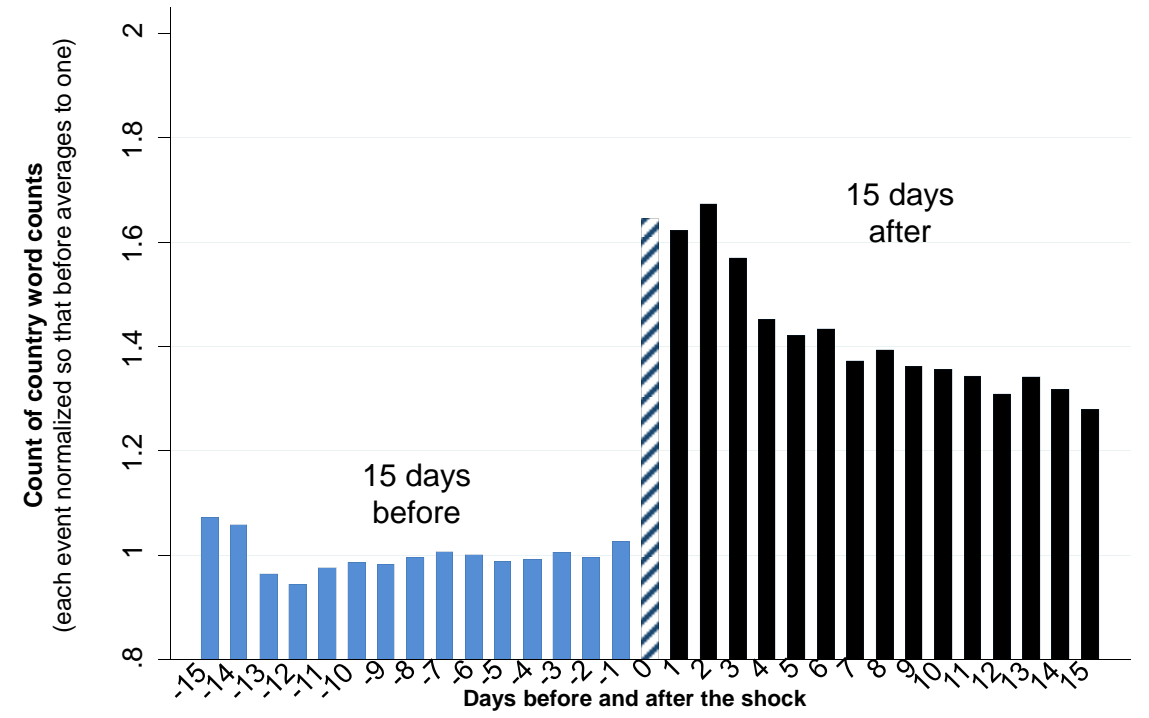

Notes for the figure: Shows the daily count of the name of the impacted country in the two weeks before and after the shock, averaged over the 1353 shocks studied in the regression analysis. For graphing purposes the series for each event is normalized so that over the 15 days before the shock it has a mean of one. In the regressions events are weighted by the increase in cites in the 15 days after the event compared to the 15 days before to focus on the jump in cites after an event.

Figure 3: Newspaper daily word counts for the affected country in the one month around national elections

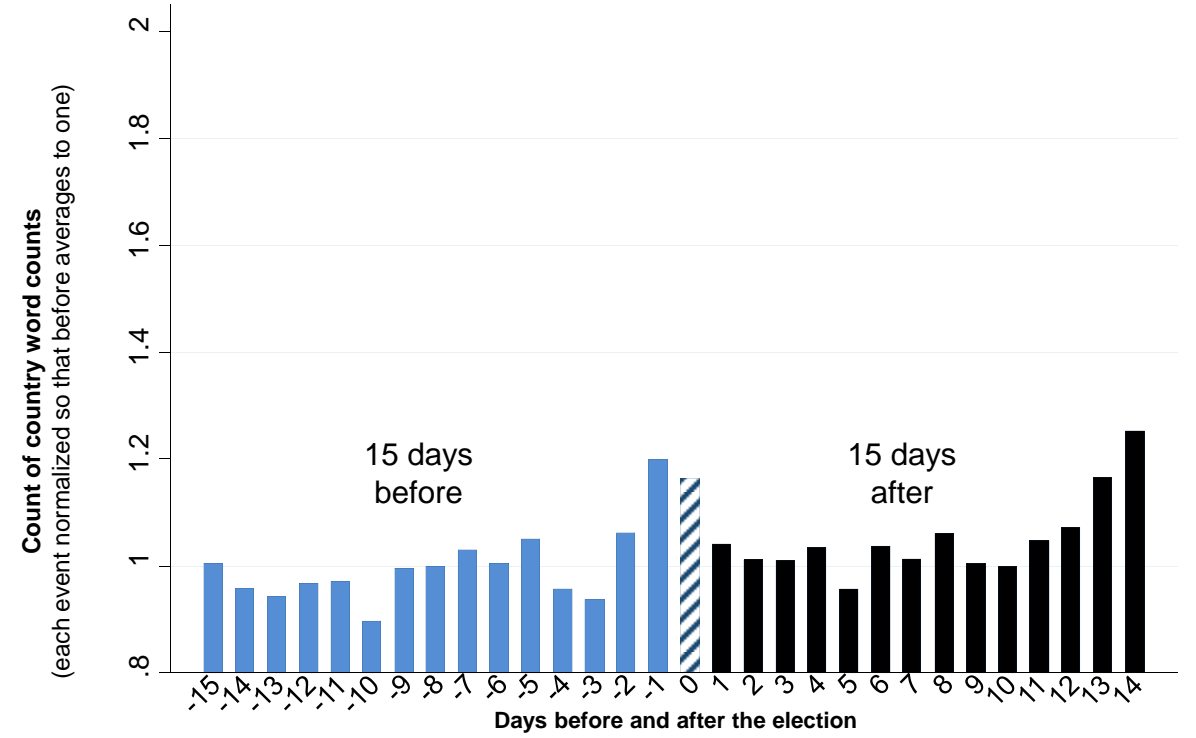

Notes for the figure: Shows the daily count of the name of the impacted country in the two weeks before and after the election, averaged over the 133 elections in the G20 countries our sample. The series for each event is normalized for graphing so that over the 15 days before the election it has a mean of one. 
conditions. As alternative estimation approaches, we also try using cross-firm stock-price returns dispersion, bond-price volatility, exchange rate volatility and forecaster disagreement measures to proxy for second moment shocks, and find similar results.

A second concern is whether these events are really shocks or are endogenous events. For example, maybe some revolutions were predicted in advance or natural disasters arising from human actions (like deforestation) could be foreseen. To address this we test our shock instruments directly and find while these have extremely high predictive power for future economic outcomes like stock returns and GDP growth, we cannot find any predictive power for these shocks using lagged stock returns and GDP growth date. Moreover, as shown in Figure 2, there is no increase in newspaper mentions of these countries in the days leading up to the day of the event, suggesting they were not anticipated in the short-run, either. We also run various over-identification tests in our regressions and find no evidence to reject the instruments. Hence, while some of the shocks may be predictable in the very long-run (for example, global warming may increase large hurricanes), over the quarterly or annual time horizon of our analysis, they appear to be unpredictable.

Third, our stock market levels and volatility indicators proxy for a range of channels of economic impact (e.g. the destruction of property after a natural disaster and the closure of the banking system after a revolution). We see these as all part of the first and second moment impacts of these shocks. But it is worth noting that in obtaining causal identification of the impact of first and second moment effects of exogenous shocks on the economy, we are conflating all these channels together.

We also investigate the impact of higher-moments of these disaster shocks - using the skewness and kurtosis of stock-market returns as proxies - and find little significant relationship. Hence, this suggests that changes in the mean and variance of economic conditions appear to be sufficient statistics for the impact of disaster shocks on the economy in our quarterly and yearly analysis. ${ }^{5}$

Finally, our results are only valid to the extent that they identify the first and second moment impact of our shocks in the countries and years that they occur. This is a classic local average treatment effect (LATE) issue (see Imbens and Angrist, 2004), in that our identification is driven by the variation in our instrument, which comes mainly in developing countries, which experience many more shocks than developed countries.

As a robustness test, we re-estimate our results using a variety of sample splits. We find very similar results for countries above and below median income levels, population sizes and time periods.

\footnotetext{
${ }^{55}$ This does not mean that higher moments are not important, as shown for example by Barro et al. (2012) and Gourio (2012). Instead, these results suggest that higher moments do not change rapidly enough after major shocks to play an important role in determining their short-run (quarterly or yearly) impact.
} 
Before presenting the empirical results we first run a micro-to-macro simulation model based on Bloom (2009) in which we introduce disaster shocks with first and second moment components. From this we generate simulated aggregate quarterly data on which we test the empirical identification strategy we use on actual data, and confirm that we can identify the true impact of first and second moment shocks. We do this simply to confirm there exists a reasonable macro framework in which the impact of first and second moment shocks can be identified using our disaster shocks methodology.

This paper links to the literature on volatility and growth. Ramey and Ramey's (1996) influential paper looked at a cross-country panel data and found a strong negative relationship between growth and volatility. Other related growth papers include Barro (1991) who finds a negative relationship between growth and political instability, Koren and Tenreyro (2007) who find strongly negative correlations between growth and the volatility of country level macro shocks, and Engel and Rangel (2008) who show a negative correlation between GARCH measures of heteroskedasticity and growth in cross country panels. Carriere-Swallow and Cespedes (2011) demonstrate that this relationship appears much stronger for emerging countries with less developed financial systems relative to the United States. As with the business cycle literature the challenge with this literature is identifying the nature of causality underlying these relationships between growth and volatility.

In section 2 we describe our estimating framework and run a simulation model to show that we obtain identification under this modeling null, in section 3 we describe our economic and disaster data, while in section 4 we run instrumental variable estimations. In section 5 we estimate a series of extension and robustness tests, and we conclude in section 6 .

\section{Model and Simulation}

To investigate the ability for our empirical approach to identify the impact of uncertainty shocks using natural disasters, terrorist attacks and political disasters we build a simulation model. This helps to both clarify the underlying economic model we have in mind, and also show that, at least in this set-up, our empirical approach is able to identify the parameters of interest.

\section{2a) Basic model}

We set up a standard micro-macro model and include disaster shocks of varying types. It is based on Bloom (2009), which itself builds heavily on prior papers like Bertola and Caballero (1994), Dixit and Pindyck (1994), Abel and Eberly (1996) and Cooper and Haltiwanger (2006). We sketch the details here, with the entire Matlab and Stata code available at www.stanford.edu। nbloom\bakerbloom1.zip.

Each firm operates using a standard Cobb-Douglas production function for output (Y) and faces an isoelastic demand curve. Combining these together yields a revenue function of the form:

$$
\mathrm{Y}=\mathrm{A}^{1-\alpha-\beta} \mathrm{K}^{\alpha} \mathrm{L}^{\beta}
$$


where A represents stochastic "business conditions" (where business conditions combine both demand and productivity shocks), $\mathrm{L}$ is labor and $\mathrm{K}$ is capital. ${ }^{6}$ Business conditions are given by a random walk with firm and macro (country) level components:

$$
\begin{array}{cc}
\mathrm{A}^{\mathrm{A}}=\mathrm{A}_{\mathrm{M}} \times \mathrm{A}_{\mathrm{F}} & \\
\mathrm{dA}_{\mathrm{M}, \mathrm{t}}=\mu_{\mathrm{M}} \mathrm{dt}+\sigma^{\mathrm{M}}{ }_{\mathrm{t}} \mathrm{dw}_{\mathrm{M}, \mathrm{t}} & \mathrm{dw}_{\mathrm{M}, \mathrm{t}} \sim \mathrm{N}(0,1) \\
\mathrm{dA}_{\mathrm{F}, \mathrm{t}}=\mu_{\mathrm{F}} \mathrm{dt}+\sigma^{\mathrm{F}}{ }_{\mathrm{t}} \mathrm{dw}_{\mathrm{F}, \mathrm{t}} & \mathrm{dw}_{\mathrm{F}, \mathrm{t}} \sim \mathrm{N}(0,1)
\end{array}
$$

Since the process is multiplicative in $A_{M}$ and $A_{F}$, we set $\mu_{M}$ to $3.8 \%$ to match the sample average GDP growth rate and $\mu_{\mathrm{F}}$ to zero. We also assume macro and micro uncertainty are driven by one joint process, $\sigma_{t}$, reflecting the empirical fact that these move together over time. ${ }^{7}$ To generate simulated high-frequency stock-returns data we run the model at a weekly frequency. ${ }^{8}$

We assume that this joint uncertainty process evolves as 2-point weekly Markov chain with the following weekly transition matrix

\begin{tabular}{|c|c|c|}
\hline & $\sigma^{\mathrm{L}}$ & $\sigma^{\mathrm{H}}$ \\
\hline$\sigma^{\mathrm{L}}$ & $\pi^{\mathrm{LL}}=0.9965$ & $\pi^{\mathrm{LH}}=0.0035$ \\
\hline$\sigma^{\mathrm{H}}$ & $\pi^{\mathrm{HL}}=0.027$ & $\pi^{\mathrm{HH}}=0.973$ \\
\hline
\end{tabular}

where $\pi^{\mathrm{ij}}$ is the probability of going from state " $\mathrm{i}$ " to state “ $\mathrm{j}$ ”. The value $\left(\pi^{\mathrm{LH}}\right)$ is calibrated to our empirical uncertainty data to ensure that uncertainty shocks happen once every 5.5 years, and the value $\left(\pi^{\mathrm{HH}}\right)$ so that shocks have a 6 month average half-life. ${ }^{9}$ Finally, we set $\sigma^{\mathrm{H}}=2 \times \sigma^{\mathrm{L}}$ based on the evidence that periods of high uncertainty after major shocks have about twice the volatility as normal times (although the qualitative results from the simulations are not particularly sensitive to these calibrations).

Capital is assumed to exogenously depreciate each period by an annualized rate of $\delta_{\mathrm{K}}$ (set at $10 \%$ per year) while labor exogenously attrits at an annualized rate $\delta_{\mathrm{L}}$ (for numerical simplicity also set at $10 \%$ per year).

To change the capital stock or labor force over and above this exogenous drift requires firms to pay adjustment costs $\mathrm{C}(\Delta \mathrm{K} / \mathrm{K})$ and $\mathrm{C}(\Delta \mathrm{L} / \mathrm{L})$. These adjustment costs include both fixed costs of adjustment for any (gross of depreciation or attrition) non-zero adjustment (that is $\Delta \mathrm{K} / \mathrm{K} \neq 0$ and $\Delta \mathrm{L} / \mathrm{L} \neq 0$ ). They also include a per-unit

\footnotetext{
${ }^{6}$ As in Bloom (2009), the specification has business conditions raised to the power (1- $\left.\alpha-\beta\right)$ to preserve homogeneity of degree one in A, K and L. This follows Abel and Eberly (1996), and allows the problem to be normalized by capital, removing a state-variable in the simulation, easing the computational burden.

${ }^{7}$ See the literature survey in Bloom, Fernandez-Villaverde and Schneider (2013).

${ }^{8}$ The model is solved by value function iteration in Matlab on a log-linear grid-space. The model has states $(\mathrm{Y} / \mathrm{K}, \mathrm{L} / \mathrm{K}, \sigma)$, where the homogeneity in $(\mathrm{Y}, \mathrm{K}, \mathrm{L})$ allows the problem to be normalized in $\mathrm{K}$ (reducing the state space by one dimension).

${ }^{9}$ The frequency matches the fact that in our data stock-market volatility is 1.65 standard-deviations above the median value every 5.5 years (where we used the 1-sided 5\% significance level as a cut-off for significant jumps in uncertainty), while the 6 month half-life is used because $\log$ (volatility) has a coefficient of 0.510 on its 6 -month lag, suggesting $50 \%$ mean reversion within 6 months.
} 
investment/disinvestment and hiring/firing costs per unit of $\Delta \mathrm{K}$ and $\Delta \mathrm{L}$ (gross of attrition). ${ }^{10}$ These adjustment costs are standard in the literature and reflect, for example, the fixed costs of closing a business to install new capital or advertising to hire new employees, and the per-unit costs of buying/selling capital and training/firing new workers. They are also important for driving the types of real-options effects of uncertainty on reducing investment and hiring that drive much of the short-run impact of uncertainty on growth.

The firm is assumed to be risk neutral and maximizes the present discounted value of all current and future revenues. ${ }^{11}$ To avoid compositional effects we assume there is no entry and exit.

\section{2b) Simulated Disaster Shocks}

As in our empirical data, we also include four types of disaster shocks in our simulation. Each shock type affects the $A_{M}$ process in a unique way through a bundle of first and second moment effects. These bundles are chosen to correspond roughly to those found in our empirical data.

The first shock type corresponds to natural disasters, and has a first moment $\left(\mathrm{dw}_{\mathrm{M}, \mathrm{t}}\right)$ effect of $-0.5 \sigma^{\mathrm{L}}$ and no second moment $\left(\sigma_{t}\right)$ effect. This reflects the empirical fact that natural disasters are typically bad for the economy (hence the negative first-moment impact) but do not generally increase uncertainty since they are a draw from a known distribution. For example, the 1995 Japan Kobe earthquake led to a 19\% drop in the stock-market but no increase in quarterly stock-market volatility.

The second shock type corresponds to coups and has a (positive) first moment effect of $0.5 \sigma^{\mathrm{L}}$ and raises uncertainty to $\sigma^{\mathrm{H}}$. This reflects the empirical fact that coups, or 'political shocks', have an average positive impact on stock-market returns, because they all (in our sample) involve coups by right-wing military groups against left-wing governments. But these political coups generate a significant increase in stock-market volatility. For example, after Musharraf led a military coup against the elected government in Pakistan in 1999 the stock-market rose by 15\% and quarterly volatility increased by nearly $200 \%$.

The third shock type approximates a revolution and has a first moment shock of $-2 \sigma^{\mathrm{L}}$ standard deviations and again raises uncertainty to $\sigma^{\mathrm{H}}$. This reflects the fact that revolutions - defined as changes of power instigated by a group outside the Government - are generally associated with left-wing guerilla uprisings, and thus have both a very large drop in the stock-market and a large increase in uncertainty. For example, after the revolution in Indonesia in 1988, the stock-market fell by $66 \%$ and quarterly volatility was 219\% above average.

\footnotetext{
10 The older literature also often includes quadratic adjustment costs, but since after controlling for aggregation Cooper and Haltiwanger (2006) and Bloom (2009) estimate these to be very small or zero, we do not include these.

${ }^{11}$ Allowing for firms to be risk-averse because of, for example undiversified macro shocks, would only increase the impact of uncertainty shocks. In this model we assume for simplicity countries are small and open, so that idiosyncratic country macro shocks can be diversified (and prices and wages are fixed).
} 
The final shock type approximates a terrorist attack with a first moment effect of $-0.5 \sigma^{\mathrm{L}}$ standard deviations and raises uncertainty to $\sigma^{\mathrm{H}}$. This reflects the fact that terrorist attacks are both bad news for the economy and also increase uncertainty, as they signal the increased probability of future terrorist attacks. For example, after the 9/11 terrorist attacks in the US the stock-market fell by $12 \%$ and quarterly volatility rose by $300 \%$.

These shocks have a probability of occurring calibrated to match their observed frequency in our actual data as shown in Table 2, which is a quarterly probability of approximately $8.6 \%$ for natural disasters, $0.25 \%$ for political shocks, $0.1 \%$ for revolution shocks and $0.5 \%$ for terrorism shocks. These disaster shocks are drawn independently each period. $^{12}$

Finally, for internal consistency we adjust the parameter values $\mu_{M}$ and $\sigma_{t}$ so that the mean and variance of the $\mathrm{dA}_{\mathrm{t}}$ matches the parameter values discussed above. ${ }^{13}$ This means in our model first and second moment shocks occur both due to disasters also due to other events, like monetary, technology of factor-price shocks.

\section{2c) Generating Simulated Data}

We assume our countries are small open economies with prices and wages fixed so we can run our simulation at the firm level and aggregate up. This is empirically reasonable as our median country is open with a mean trade/GDP ratio of 0.83 , and is computationally much easier as we do not need to address issues around general equilibrium. ${ }^{14}$

We run our simulation weekly for 500 firms per 'country' for 10,000 'countries' for 30 years. From this weekly level, we generate three series of quarterly data for each country. The first is quarterly data on overall output summed across all firms and weeks. The second is stock return data taken from the return over the quarter from holding all firms. Finally, we also generate stock volatility data from the 13 sets of weekly stock returns.

We also allow for high-frequency noise in measured stock-market returns, for-example from noise-traders, which is likely to be common in many of the countries examined in

\footnotetext{
12 In the unlikely event that two occur their impact is additive. For example, a natural disaster and a terrorism shock in our simulation would generate a $-\sigma^{\mathrm{L}}$ shock to dw $\mathrm{w}_{\mathrm{M}, \mathrm{t}}$ and an increase in uncertainty to $\sigma^{\mathrm{H}}$.

13 The disasters generate an expected annual first moment shock of $-0.4 \%$, calculated from summing up the probability*expected impact of natural disasters, political shocks, revolution shocks and terrorist attacks (where $-0.004=-0.086 * 0.1 \sigma^{\mathrm{L}}+0.002 * 0.1 \sigma^{\mathrm{L}}-0.001 * 0.5 \sigma^{\mathrm{L}}-0.0005^{*} .1 \sigma^{\mathrm{L}}$ given $\sigma^{\mathrm{L}}=0.443$ ). So the underlying driving process in the absence of disaster shocks has a drift $\left(\mu_{\mathrm{M}}\right)$ of $4.2 \%$ to ensure after disasters shock the process has a mean annual growth rate of 3.8\%. In terms of the variance the probability of entering highuncertainty from disaster shocks is 0.0035 per year, or about 0.0001 per week, so that $\pi^{\mathrm{LH}}$ is adjusted down to 0.0034 so that including disasters shocks leads to high uncertainty weekly probability of 0.0035 .

14 As Bloom, Floetotto, Jaimovich, Saporta and Terry (2012) show, general equilibrium prolongs and dampens, but does not eliminate, the impact of uncertainty shocks. In the simulation prices are taken as the numeraire, while wages are set of unity because of the free scaling parameter (wages impact firm size but not growth rates).
} 
our empirical section. To do this we assume that weekly stock-returns are measured with i.i.d. noise with a variance equal to the fundamental variation. That is

$$
r_{i, t}=r_{i, t}+e_{i, t} e_{i, t} \sim N\left(0, \sigma_{r}^{2}\right)
$$

where $r_{i, t}$ is the simulation measured return in country i in period $t, r_{i, t}$ is the fundamental return (from the value function), and $e_{i, t}$ is i.i.d white-noise with a variance $\sigma_{\mathrm{r}}{ }^{2}$ (where $\sigma_{\mathrm{r}}^{2}$ is the variance of $\left.\mathrm{r}_{\mathrm{i}, \mathrm{t}}\right){ }^{15}$

\section{2d) Results on the Simulated Data}

In Table 1, we give results from our simulated economy with disaster shocks, first from OLS and then instrumenting for volatility and stock market returns with the four types of simulated disaster shocks (natural, political, revolution, terrorist). To calculate standard errors comparable to our actual data sample of 60 countries we block bootstrap at the country level with replacement over samples of 60 simulated countries. ${ }^{16}$

Columns (1) and (2) show our OLS results regressing GDP growth in our simulated data on our simulated stock market returns level and volatility over the past year. We find larger coefficients at a yearly level in column (2) compared to the quarterly results in column (1), consistent with stronger associations estimated over a longer time period. The reason for these larger long-run coefficients on stock-returns and volatility is that the mean and variance of returns are measured more precisely at an annual level than a quarterly level, since the former has 13 observations and the latter 52 observations per period. ${ }^{17}$ As we shall see in section 4 a similar pattern of larger coefficients in yearly versus quarterly regressions is also present in the real data.

Columns (3) and (4) display our IV results utilizing our simulated data. In both the quarterly results and the annual results, we find higher point estimates than those in the corresponding OLS results. This is due to endogeneity biasing down our OLS results. This endogeneity bias arises because first moment shocks to aggregate business conditions $\mathrm{A}_{\mathrm{M}}$ also generate stock-market volatility effects, and second moment shocks to uncertainty $\sigma$ have positive levels effects through the Oi-Hartman-Abel effect. ${ }^{18}$ As a result, stock market levels and volatility measures conflate the offsetting impacts of the underlying first and second moment shocks, and so both sets of coefficients are biased towards zero under OLS.

\footnotetext{
${ }^{15}$ Hence, at the weekly frequency the signal:noise ratio in stock returns is 1:1, but over longer horizons this will be greater than 1 (due to the i.i.d. nature of the noise).

${ }^{16}$ Block bootstrap means we sample with replacement at the country (rather than observation) level. This means we obtain the point estimates from the full simulation sample of 10,000 countries, but the standard errors from the empirically realistic sample of 60 countries assuming countries are randomly drawn.

${ }^{17}$ There are two reasons for the greater precision in larger samples. Firstly, the measurement error in the simulation is iid, so it averages out in larger samples. Secondly, the variance of the sample mean and sample variance fall by order $1 / \mathrm{N}^{1 / 2}$ and $1 / \mathrm{N}$, so that moving from quarterly to yearly data increases the accuracy of the sample estimates of the mean and variance of underlying business conditions.

${ }^{18}$ This reflects the fact that with flexible factors of production a mean preserving spread in business conditions increases the expected marginal revenue product of the factors (see Oi (1961), Hartman (1972) and Abel (1983) for various formulations of the underlying idea).
} 
In the first stages shown below the second stage results, we find that political, revolution and terrorist shocks increase the volatility of stock returns, while natural disasters have a positive point estimate but are not significant. Consistent with the simulation we find negative effects on returns for all shocks except for political shocks, where we find a significantly positive effect. Moreover, both IV regressions pass weak instruments and over-identification tests, suggesting that utilizing bundles of shocks and controlling only for first and second moment shocks are viable methods of obtaining the correct sign of the causal effect of uncertainty.

In column (5) of Table 1 we examine to what extent in the simulation our disaster instruments provide identification for the correct magnitude of the sample average impact of first and second moment shocks on growth. To do that we present results for the estimation in which we instrument stock-market returns levels and volatility using the true underlying process for $A_{t}$ and $\sigma_{t}$. While we clearly cannot observe the true underlying first and second moment shock process in real data, in the simulation we can directly observe them. This enables us to compare the ability of the bundle of disaster shocks to proxy for these true shocks. Comparing between the estimates in columns (4) and (5) we see that the point estimates on the stock-market levels and volatility measures are very similar across the two specifications. This highlights that fact that - at least in our simulation - using disaster shocks as proxies for the underlying first and second moment shocks is a consistent estimation strategy. ${ }^{19}$

In summary, this short simulation section demonstrates that under the null of: (i) a standard Cobb-Douglas production model with stochastic first and second moment shocks, (ii) disaster shocks that are different bundles of these underlying shocks, and (iii) stock market values that are noisy measures of true firm valuations, we can use disasters as instruments for stock-market valuations to estimate the relative contribution of first and second moment shocks on GDP growth.

\section{Data}

In the estimations with real data we use 60 countries in our analysis. These are selected as countries with more than $\$ 50$ billion in nominal GDP in 2008. We also required at least 5 years of daily stock returns data from a national index. While a number of countries have data beginning in the 1940s, most countries have relatively complete data starting only in the 1970s or later. Thus, we construct our sample from 1970 onwards in order to avoid early years with only a few countries with data in our panel. The data can be divided into disaster shock data and economic data, which we now discuss in turn, and are summarized in Table 2.

19 Another experiment we undertook is assume the first moment shock destroyed part of the capital stock rather than reduce TFP, finding very similar results in the estimations. The reason is in the production function $Y=A^{1-\alpha-\beta} K^{\alpha} L^{\beta}$ reductions in $K$ have a similar impacts on firms' value as reductions in $A$. 


\subsection{Disaster shock Data}

To obtain the causal impact of first and second moment shocks on GDP growth we want to instrument using arguably exogenous shocks. This leads us to focus on natural disasters, terrorist attacks, and political shocks, which are typically exogenous at least in the short-run. This approach has some precedent in the literature, such as a paper by Jones and Olken (2005) looking at successful assassinations of national leaders as an instrument for leadership change and in Hoover and Perez (1994) who use oil-price shocks as instruments for aggregate productivity shocks. Furthermore, others have found strong effects of political 'shocks' on markets and asset prices, as in Zussman, Zussman, and Nielsen (2008).

As we discuss below, the exogeneity of many of these shocks is disputable in the longrun. For example, faster economic growth may increase the chances of a natural disaster through reduced forest cover, but reduce the chances of a revolution by lowering poverty rates. To address this concern, we do three things.

First, we focus only on short-run impacts of shocks, looking only at one year impacts in the regressions. At these short-run frequencies it is easier to argue shocks are exogenous. For example, while many commentators expected revolutions in the Middle East at some point over the next couple of decades, the start of the Arab Spring in December 2010 was unexpected. Second, we weight shocks by the increase in media coverage 15 days after the event compared to 15 days before the event. This should remove anticipated shocks in that the media coverage running up to them would be smoothly increasing. Figure 1 shows this media coverage on average for all shocks combined, displaying a large 39\% jump after the shocks and no obvious run-up in coverage before the event. In comparison, Figure 2 shows the media coverage in the one month around general elections with no jump in the 15 days after the event.

Third, we do a variety of robustness tests and tests of the exogeneity of our shocks and find the results reassuringly robust. For example, as shown in Table A1 these shocks cannot be forecast in advance by stock market data, suggesting they are not anticipated by the market at a quarterly or annual level.

We now discuss the definitions of each of these three groups of shocks in turn, and note that all data-sets and do-files to replicate every result and regression are available online at www.stanford.edu $\sim$ nbloomlbakerbloom2.zip .

One initial issue is that the number of events covered by natural, political and terrorist disasters is extremely large, typically with several events per week around the world. So we need to apply a filter to focus only on major events. With this aim, we include a shock only if it fulfills at least one of the following conditions (our results are robust to modification of filters for both deaths and monetary damages, or by utilizing an absolute filter, instead of one relative to a country's characteristics, as shown in our data file):

1. More than $.001 \%$ of a country's population dead

2. More than $.01 \%$ of a country's GDP in damage

3. A successful coup or regime change 
Table 3 contains some summary statistics of our country sample, economic and shock variables. We have around 6000 quarterly observations for the 60 countries with full GDP growth and stock returns data, with over 1000 shocks occurring over this period. Included for each shock, in parenthesis, are the quarter the shock occurred in, the ratio of news citations for the 15 days following the shock to the 15 days preceding it, and the type of shock (Natural Disaster, Political, Revolution, or Terrorism).

Natural Disasters: Our natural disaster data has been obtained from the Center for Research on the Epidemiology of Disasters (CRED). ${ }^{20}$ This dataset contains over 15,000 extreme weather events such as, droughts, earthquakes, epidemics, floods, extreme temperatures, insect infestations, avalanches, landslides, storms, volcanoes, fires, and hurricanes from 1960 to 2013. The dataset includes the categorized event, its date and location, the number of deaths, the total number of people affected by the event, and the estimated economic cost of the event. The CRED dataset also includes industrial and transportation accidents which we exclude in our analysis.

Terrorist Attacks: To define terrorist events we use the Center for Systemic Peace (CSP): High Casualty Terrorist Bombing list, which extends from 1993-2012 and includes all terrorist bombings which result in more than 15 deaths. ${ }^{21}$ This data includes the location and date of each event as well as the number of deaths and an indicator for the magnitude of the attack ranging from 1 to 6. As this data only extends from 1993-2012, we supplement it with a list of high death-toll terrorist attacks from Wikipedia's "violent events" page. ${ }^{22}$ This data includes attacks with greater than 30 deaths and the covers 1920-2013.

Political Shocks: For political shocks, we utilize data from the Center for Systemic Peace (CSP): Integrated Network for Societal Conflict Research. To define political shocks we include all successful assassination attempts, coups, revolutions, and wars, from 19702012. Again, to supplement this measure, we utilize the list of coups and revolutions from Wikipedia for political shocks in 2012 and $2013 .^{23}$

We include two types of political shocks, each derived from the CSP's categorization of political shocks which is based on the types of actors and motives involved. The first is

\footnotetext{
${ }^{20}$ See http://www.emdat.be/database CRED is a research center which links relief, rehabilitation, and development. They help to promote research and expertise on disasters, specializing in public health and epidemiology. Their EM-DAT database is an effort to provide a standardized and comprehensive list of large-scale disasters with the aim of helping researchers, policy-makers, and aid workers better respond to future events.

${ }^{21}$ See http://www.systemicpeace.org/inscr/inscr.htm The CSP is a research group affiliated with the Center for Global Policy at George Mason University. It focuses on research involving political violence in the global system, supporting research and analysis regarding problems of violence in societal development. The CSP established the Integrated Network for Societal Conflict Research in order to coordinate and standardize data created and utilized by the CSP.

22 http://en.wikipedia.org/wiki/List_of battles_and_other_violent events by death_toll\#Terrorist_attacks Also, note, as Table 6 shows the main results are robust to using post 2000 data, which excludes any Wikipedia sourced data. When Wikipedia does overlap with the CSP data they are extremely similar.

${ }^{23}$ http://en.wikipedia.org/wiki/List_of_coups_d\%27\%C3\%A9tat_and_coup_attempts_since_2010
} 
composed of coup d'états and other regime changes. Coup d'états are defined as forceful or military action which results in the seizure of executive authority taken by an opposition group from within the government. This opposition group is already a member of the country's ruling elites, rather than, for example, an underground opposition group. Typically these are coups brought by the military or former military officers in government against left-wing governments.

Our second type of political shock denotes a revolutionary war or violent uprising. These are composed of events featuring violent conflict between a country's government and politically organized groups within that country who seek to replace the government or substantially change the governance of a given region. These groups were not previously part of the government or ruling elite and generally represent left-wing rebels overthrowing a right-wing or military regime. This category also does not include political violence stemming from ethnic grievances.

Within each category, by country and quarter, we give a value of one if a shock has occurred and a zero otherwise. This means that if a country has, for example, three earthquakes in one quarter, it still only receives a value of one. When using the mediaweighted shocks, we use the shock with the highest jump in media citations for that category in that quarter. The reason is to avoid double counting recurring but linked events within a quarter - such as an earthquake with multiple aftershocks.

\subsection{Economic data}

Output Data: Real GDP is obtained from the Global Financial Database for all but 15 countries. GDP data for Mexico, Venezuela, Chile, Greece, and Singapore was obtained from the IMF Statistics division. GDP data for Pakistan was obtained from the World Bank. Saudi Arabian GDP data was obtained from the World Development Indicators Database. GDP data for Bangladesh, Kenya, Kuwait, Serbia, and Vietnam was obtained from the World Economic Outlook database. Finally, GDP data is proxied for by Industrial Production for Poland, Romania, and Nigeria. Real GDP data is denominated in the local currency and its reference year varies. As we deal with percentage changes, the different denominations and base years of different countries does not matter.

We use yearly real GDP growth by quarter (year-on-year growth in quarterly) as our primary dependent variable to remove seasonality and quarterly effects, and reduce the impact of high frequency measurement errors. In some specifications we also use quarterly GDP growth defined as growth in GDP between the current and preceding quarter.

Annual population data for all data was obtained from the Global Financial Database. Population data is taken from national estimates and represents annual December $31^{\text {st }}$ population levels. Data on monthly Consumer Price Indexes is obtained for all countries from a variety of sources, primarily the GFD, OECD, and the IMF.

Stock Market Data: Data on stock indices was obtained from the Global Financial Database, using the broadest general stock market index available for each country. 
Wherever possible we used daily data, but for seven countries we used weekly or monthly data in the 1980s and early 1990s to construct stock returns and volatility indices when daily data was not available. ${ }^{24}$ Our results are robust to the exclusion of observations taken from non-daily stock data and to excluding all observations from these countries. All stock indices in our analysis are normalized by the country level CPI data to obtain real returns.

In the empirical specifications, we generate yearly stock returns in each quarter, defined as the cumulative return over the proceeding four quarters, in order to match our yearly GDP growth rates. A measure of average yearly volatility is created by taking the average of quarterly standard deviation of stock daily returns over the last four quarters. We also utilize a number of alternate measures of first and second moment shocks as robustness tests for which we show cross-correlations in Table A2.

Cross Sectional Firm Return Data: We also employ a micro-focused measure of first and second moment shocks, looking at returns across individual firms. We employ data from the WRDS international equity database, using data from all countries in our sample which have daily data from greater than 10 listed firms (comprising 42 of the 60 countries in our main sample). We use the average of firm-level stock returns within a country as a measure of first moment shocks. We then use the standard deviation of quarterly returns across firms as our second moment.

Bond Yield Data: We take daily 10-year Government bond yield rates as an additional measure of volatility. We construct volatility from the quarterly volatility of daily percentage changes in bond yields, and the first moment from the mean quarterly bond yield.

Exchange Rate Data: We also collect daily exchange rate data from the Global Financial Database whenever available, and use the quarterly volatility of daily percentage change of exchange rates as an alternative measure of uncertainty.

Forecaster Disagreement Data: We use the Consensus forecast database which collects data from forecasters for a variety of outcomes including GDP across different countries. For countries with more than 10 forecasters on average (23 of our sample of countries) we compute the span of one year ahead GDP growth forecasts as a measure of uncertainty and the mean of this as a measure of the first moment.

\subsection{News Citations}

Two natural concerns are that the shocks we utilize as instruments are either not unexpected or relatively small in magnitude. In order to help alleviate both of these potential problems, we turn to a measure of unexpectedness and impact derived from news article mentions of the countries in question.

\footnotetext{
${ }^{24}$ These countries are Saudi Arabia, Mexico, South Africa, Ireland, Russia, Turkey, and Venezuela.
} 
Using the Google News Archives, we construct an "attention" index surrounding each event. For each event we search the Google News Archives using the name of the country the event occurred in. We then observe a 15 day period on either side of the day of each event, counting the number of articles written each day about the country. Figure 2 reports the average number of articles on the country surrounding the event, where each event's coverage has been normalized to 1 in the 15 days prior to the event.

We use this data to construct a measure of the jump in attention paid to the country subsequent to an event or disaster. This will help to distinguish events which were both unexpected and large enough in magnitude to plausibly affect national returns or volatility from those which were not. For example, if we observe a similar number of articles regarding the country before and after the event date, we can assume that the event was predicted ahead and/or it was not that important. In contrast, observing a jump in news articles just after the event makes it likely this was (at least in part) both unexpected and important enough to command additional news attention.

The way we define our jump in coverage index is to compute the percentage increase in the number of articles written in the 15 days after the event compared to the 15 days before the event. We choose this narrow 15-day window either side of the event to maximize our ability to detect discrete jumps in coverage (longer windows will also include gradual trends), and to minimize the chances of feedback from economic impacts of event onto our index. As an illustration of this approach if we see 15 articles written about a country in the 15 days prior to the event and 30 articles written about a country in the 15 days following an event, we would assign this event a weight of 1 as it reflects a $100 \%$ jump in citations. Results are broadly robust to using narrower or wider windows, like 5 or 30 days, surrounding the event.

\section{The Impact of Uncertainty on Output}

We display results from our primary specifications in Table 3. Columns (1) and (2) give results from OLS regressions of national GDP growth on stock market returns and volatility. We find a significant positive coefficient on stock returns and a significant negative coefficient on stock market volatility. Furthermore, we find a large increase in the measured effect when we move to the yearly OLS specification, exactly as in our simulation results. ${ }^{25}$ One reason for a higher yearly coefficient is that stock-volatility is likely to be a less noisy proxy for uncertainty, since it spans about 255 daily observations per year (in comparison to around 64 per period for quarterly data). Another reason is the yearly specification allows up to one year for the impact of these shocks to arise, capturing the fuller impact compared to looking at just one quarter.

However, we worry about a high degree of endogeneity in these OLS results, so we proceed to our instrumental variable (IV) regressions. Columns (3) and (4) show results from our quarterly and yearly IV regressions. Here we instrument for stock returns and

\footnotetext{
${ }^{25}$ Note that while the relative parameter values are similar in the simulation and actual data the levels are different, due to relative differences in units and measurement error. By rescaling the units of the simulated data we could more closely align the parameters values, but since the objective is to show relative differences across parameters we have not done this to increase transparency.
} 
volatility with our set of scaled disaster shocks. This set consists of four series: natural disasters, political shocks, revolutions, and terrorist attacks.

Before discussing the second stage results we first check the first-stage results. These look very good in that the F-tests of the set of disaster shocks have values of around 50 or above, and for the preferred yearly specification these are 54.33 for stock levels and 59.09 for stock volatility. In terms of specification tests the Sargan over-identification test is not rejected on either specification, suggesting that the impacts of these four types of disaster shocks are fully captured by stock-market levels and volatility. That is, it appears that observing the impact of these disaster shocks on stock market levels and volatility is a sufficient statistic for their one-year impact on GDP growth.

In terms of the individual instruments there is a significant positive effect for political shocks and revolutions, but nothing significant for natural disasters or terrorist attacks. This suggests that while sudden changes in government increase uncertainty, natural disasters and terrorist attacks do not, presumably as they are typically one-off bad events. For returns we find negative effects for revolutions and terrorist attacks, but perhaps surprisingly positive effects of political shocks on stock market returns. This stems from the nature of these political coup shocks, which are generally right-wing military coups that often take power from left-wing governments. In contrast, revolutions are generally left-wing groups overthrowing military or right-wing governments. Intriguingly we find negative but insignificant effects of natural disasters on stock market returns. One possible explanation is because increased foreign aid and reconstruction following natural disasters offsets some of the capital destruction they cause. ${ }^{26}$

Turning to the second stage results we see a significant causal impact of both first and second moment effects on economic activity. The magnitudes of the impacts are large. For example, on the preferred yearly specification we find that a one-standard deviation first-moment shock increases GDP by about 2.2\% over the following year (about a half a standard deviation of GDP growth) and a one standard-deviation second moment shock reduces GDP by about 7.1\% (about 1.5 standard deviations of GDP growth).

In column (5) rather than use the volatility of daily aggregate stock-market indices to measure uncertainty we instead use the cross sectional dispersion of quarterly returns across individual companies. This provides an alternative measure of uncertainty that has been used frequently in the literature (for example, Campbell et al. (2002)). Since we are using firm-level returns to measure uncertainty in column (5) we also use (average) firmlevel quarterly returns as our first moment proxy. We find similar point estimates and magnitudes, but in part due to our smaller sample (for many countries we do not have individual firm stock-returns) the significance is lower.

Finally, in column (6) we use the principal component factor of the aggregate and crosssectional measures for uncertainty and returns. Since both are potentially noisy measures of uncertainty their common movement may be more informative. We do indeed find significant negative effects of uncertainty and positive effects of first-moment shocks,

${ }^{26}$ See, for example, Fomby, Ikeda and Loyaza (2011) 
with again the magnitudes suggesting that a one standard-deviation change in uncertainty has about twice as large an impact on GDP growth as a one-standard deviation change in the first moment.

Interestingly, all four IV specifications give point estimates much higher than those found in the corresponding OLS regressions. We posit that this could be due to a number of factors. The first is endogeneity, as in our simulation results, whereby positive first moment shocks can generate increased stock-market volatility and second-moment shocks can have first moment effects. This causes OLS coefficients to be downward biased for both the levels and volatility terms. The second is measurement error, due to noise trading and the imperfect match in economic coverage between real activity and stock-market returns. ${ }^{27}$ Finally, an element of the Latent Average Treatment Effect (LATE) may be present. Our disaster shock instruments are more prevalent among the poorer countries in our sample where the impact of volatility may be higher than in rich countries, which we investigate in section 5.

Summary: From these results, we can discern three primary points. The first is that we find both first and second moment shocks matter to growth and that excluding either will lead to misspecification bias. In terms of magnitudes in our preferred annualized IV specification we see that a one-standard deviation shock to uncertainty has about twice the impact on GDP growth as a one standard-deviation shock to the first moment, suggesting second moment shocks are as least as important as first moment shocks in explaining yearly GDP growth. Interestingly, this is consistent with the finance literature which uses a different empirical strategy to come to a similar conclusion that first and second moment effects are about equally important for determining asset prices (e.g. Bansal and Yaron, 2004).

Second, the causal effect of uncertainty on growth appears much higher than OLS estimates suggest due to factors such as measurement error and endogeneity, consistent with our simulation results.

Finally, we find that our strategy passes the Sargan over-identification test, suggesting that controlling for the first two moments of business condition shocks (here, stock returns and stock volatility) is sufficient to capture the full short-run effect of such shocks, again consistent with our simulation results.

\section{Robustness and Extensions}

In this section we investigate the robustness of these results to including higher-moments, to different measures of first and second moments, and to a variety of sample splits.

\footnotetext{
27 As mentioned earlier stock market indices cover publicly quoted firms global activities while GDP figures cover all firms' domestic activities. These can differ for at least two reasons. The first is that many large companies have much of their operations abroad, so for that example firms like General Electric, British Petroleum and Nissan have more than 50\% of their employees abroad but their full market capitalization in their domestic stock-market indices. Second, almost all small and medium companies, and even many large companies are privately held so that stock-market indices do not cover them. Beyond this other differences arise due from, for example, timing (Calendar year versus account years) and accounting rules (Census versus GAAP rules on capital equipment depreciation).
} 


\subsection{Testing for higher moments effects}

In Table 4 we consider the impact of including higher moments - in particular skewness (the $3^{\text {rd }}$ moment) and kurtosis (the $4^{\text {th }}$ moment) - in both the OLS and IV specifications. Since all of the individual moments are cross-correlated we focus on regressions with all four of these moments included. Column (1) shows the OLS results for all four moments using our baseline aggregate returns and uncertainty measure. This reveals as before a positive first moment and negative second moment correlation, and interestingly a negative third moment relationship. The fourth moment (kurtosis) shows no significant relationship. In column (2) we re-estimate this specification and find all four moments are insignificant, in large part because they are so collinear with each other. In column (3) we solely include skewness and kurtosis but again find no significant result (noting that if we only include the first and second moments these are statistically significant as shown in Table 3). Columns (4) to (6) repeat this using the cross-firm measures of returns and uncertainty, and find again significant positive first moment and significant negative second moment effects, but little on skewness or kurtosis.

Hence, in summary there appears to be no strong evidence for any additional impact of higher moments from disasters shocks once the first and second moments are controlled for. Thus, the first and second moments of stock returns appear to be adequate proxies for the one-year impacts of disaster shocks. ${ }^{28}$

\subsection{Alternate Measures of $1^{\text {st }}$ and $2^{\text {nd }}$ Moment Shocks}

Table 5 gives four alternate measures of $1^{\text {st }}$ and $2^{\text {nd }}$ moment shocks to business conditions in addition to our baseline measure utilizing stock prices. Column (1) displays our baseline measure along with the impacts of a 1 standard deviation increase in the measured $1^{\text {st }}$ and $2^{\text {nd }}$ moments, while column (2) repeats the cross firm returns from Table 3, again revealing negative effects of volatility and positive effects of returns. Columns (3) and (4) give results utilizing the level and volatility of bond yields and the level and volatility of exchange rates as measure of first and second moment shocks. These provide alternative fixed-income and international trade related measures of uncertainty. We again find positive effects of the first moment shocks and negative effects of the second moment shocks.

Finally, in column (5) we instead use our GDP forecaster panel, using the mean and span as measures of the first and second moment. The sample is smaller here as it spans only the 23 countries with $10+$ forecasters in the Consensus database, typically the larger and wealthier countries. We see as before a positive first moment coefficient on mean GDP growth and interestingly a negative significant coefficient on GDP forecast spread. This

28 One point to clarify, however, is that this does not mean that disaster shocks' higher moments do not matter, but rather that these are not time-varying. This is in fact consistent with the frameworks of, for example, Barro et al. (2012) and Gourio (2012), who model higher moments as important but time stationary, even if some of the first and second moments vary over time. 
suggests that the dispersion of GDP forecasts - a classic proxy of uncertainty - is associated with lower growth rates.

\subsection{Robustness and heterogeneity}

Table 6 gives the results of a number of robustness exercises. Column (1) gives our baseline yearly IV regression for comparison. Column (2) shows results when we exclude our media-citation weighting of the disaster shocks. We find largely similar and still significant results. In column (3) we weight by country population, again finding similar results. In column (4) we exclude natural disasters as an instrument since these are by far the largest category of shocks - accounting for $80 \%$ of all media weighted shocks - and find the results are again robust.

Finally, in columns (5) to (7) we examine to what extent our results are heterogeneous across countries. To do this we include various dummies based on sample characteristics, splitting these at the sample mean, and investigating if our first or second moment proxies vary across these subgroups. In column (5) we include interactions with being a "rich" country, defined as being above the sample-average GDP per capita of \$25,000. Interestingly, we find no significant interaction (albeit with a large magnitude suggestive of a smaller impact of uncertainty in developed countries). In column (6) we interact by population size, and find no difference, and in column (7) be pre/post 2000 and again find no significant differences.

\section{Conclusions}

A recent body of research has highlighted how uncertainty is counter cyclical, rising sharply in recessions and falling in booms. But what is the causal relationship? Does rising uncertainty drive recessions, or is uncertainty just an outcome of economic slowdowns?

In this paper, we perform two analyses designed to determine the direction of causality. First, we perform a simulation in which a modeled economy undergoes shocks to business conditions and test the effects of these shocks, finding significant effects of both first and second moment shocks. Second, we construct cross country panel data on stock market levels and volatility as proxies for the first and second moments of business conditions. We then build a panel of indicators for natural disasters, terrorist attacks and political shocks, and weight them by the change in daily newspaper coverage they induce.

Using these shocks to instrument our stock market proxies for first and second moment shocks, we find that both first and second moment shocks are highly significant in driving business cycles, conforming well to our simulated results. And controlling for first and second moments is sufficient to determine true effects of shocks on growth, with no significant impact on growth of higher moment shocks. These results are consistent across a number of different measures of first and second moment shocks to business conditions. We also find that IV estimates of the effects of uncertainty are much larger than OLS estimate, suggesting that measurement error and endogeneity are significant concerns in OLS analyses. 


\section{Bibliography:}

Abel, Andrew. (1983): “Optimal Investment Under Uncertainty,” American Economic Review, 73, pp. 228-233.

Albagli, Elias (2011), “Amplification of Uncertainty in Illiquid Markets”, USC mimeo.

Alexopoulos, M. and J. Cohen, 2009a. "Nothing to Fear but Fear itself? Exploring the effect of economic uncertainty”, Manuscript, University of Toronto working paper.

Arrellano, Cristina, Bai, Yan and Kehoe, Patrick (2010): "Financial Markets and Fluctuations in Uncertainty,” Federal Reserve Bank of Minneapolis Research Department Staff Report.

Arslan, Yavuz, Atabek, Ashhan and Sahinoz, Saygin (2011), "Expectation errors, uncertainty and economic activity”, Bank of Turkey mimeo.

Bachmann, Ruediger, Elstner, S, and Sims, Erik (2011): "Uncertainty and Economic Activity: Evidence from Business Survey Data”, NBER WP 16143.

Bachmann, Ruediger. and Christian. Bayer (2011): “Uncertain business cycles: really?”, CESIFO-WP 2844.

Bachmann, Ruediger, Ricardo. Caballero and Eduardo. Engel (2010): “Aggregate Implications of Lumpy Investment: New Evidence and a DSGE Model”, mimeo Yale University.

Bachmann, Ruediger., and Giuseppe. Moscarini. (2011) "Business Cycles and Endogenous Uncertainty,” Yale mimeo.

Bansal, R. and Yaron, A. (2004), "Risks for the long run: a potential resolution of asset pricing puzzles", Journal of Finance LIX(4), 1481-1509.

Barro, Robert, 1992, “Economic Growth in a Cross Section of Countries,” Quarterly Journal of Economics, Vol. 106, No. 2, pp. 407-443.

Barro, Robert, Nakamura, E., Steinsson, J and Ursua, J., (2012), "Crises and recoveries in an empirical model of consumption disasters", Harvard mimeo.

Berger, D., and J. Vavra (2010): "Dynamics of the U.S. Price Distribution,” Yale mimeo

Bernanke, B. (1983): "Irreversibility, Uncertainty and Cyclical Investment,” Quarterly Journal of Economics, 98, pp. 85-106.

Bertola, G., and R. Caballero. (1994): "Irreversibility and Aggregate Investment," Review of Economic Studies, 61, pp. 223-246.

Bianchi, Francesco, and Melosi, Leonardo (2012), "Dormant shocks and fiscal virtue", Duke/Chicago Fed mimeo

Bloom, Nick. (2009): “The Impact of Uncertainty Shocks,” Econometrica, 77, pp. 623-685.

Bloom, Nick., S. Bond, and J. Van Reenen (2007): "Uncertainty and Investment Dynamics," Review of Economic Studies, 74, pp. 391-415.

Bloom, N. M. Floetotto, N. Jaimovich, I. Saporta and S. Terry, (2011), "Really Uncertain Business Cycles,” Mimeo, Stanford.

Bloom, N., and J. Van Reenen (2007): "Measuring and Explaining Management Practices Across Firms and Countries," Quarterly Journal of Economics, 122, pp. 1351-1408.

Campbell, J., Lettau, M., Malkiel B. and Xu, Y. (2001), "Have Individual Stocks Become More Volatile? An Empirical Exploration of Idiosyncratic Risk", Journal of Finance, 56(1), 1-43.

Carriere-Swallow, Yan and Cespedes, Luis F. (2011): "The Impact of Uncertainty Shocks in Emerging Economies”, Bank of Chile Working Paper.

Christiano, Lawrence, Motto and Rostagno. (2010): "Financial Factors in Business Cycles," mimeo Northwestern University.

D’Erasmo, Pablo and Moscoso-Boedo, Hernan (2011), “Intangibles and endogenous firm volatility over the business cycle”, UVA/Maryland mimeo.

Dixit, A. and R. Pindyck (1996): Investment Under Uncertainty. Princeton, NJ: Princeton University Press.

Engle, R.F. and Rangel, J.G. (2008), "The Spline-GARCH Model for Low-Frequency Volatility and Its Global Macroeconomic Causes", Review of Financial Studies, 21(3), 1187-1222. 
Fajgelbaum, Pablo, Schaal, Eduardo and Matthieu Taschereau-Dumouche (2012), "Uncertainty traps" UCLA mimeo

Fernandez-Villaverde, Jesus, Pablo Guerron, Juan Rubio-Ramirez \& Martin Uribe (2011), "Risk Matters: the real effects of volatility shocks", forthcoming American Economic Review.

Fomby, T, Ikeda, Y. and Loyaza, N. (2011), "The growth aftermath of natural disasters”, Journal of Applied Econometrics.

Gilchrist, S., J. Sim and E. Zakrajsek (2009). "Uncertainty, Credit Spreads and Aggregate Investment”, Boston University mimeo.

Gilchrist, S., and J. Williams. (2005): "Investment, Capacity and Uncertainty: A Putty-Clay Approach,” Review of Economic Dynamics, 8, 1-27.

Gourio, Francois (2012), "Disaster risk and business cycles”, forthcoming American Economic Review.

Guvenen, Fatih, Ozkan, Serder and Song, Jae (2013), “The nature of countercyclical income risk", university of Minnesota mimeo.

Hamilton, J.D. and Lin, G. (1996), "Stock Market Volatility and the Business Cycle", Journal of Applied Econometrics, 11(5), 573-593.

Hartman, Richard (1972), "The effect of price and cost uncertainty on Investment", Journal of Economic Theory, 5, 258-266.

Hassler, J. (1996): "Variations in Risk and Fluctuations in Demand-A Theoretical Model," Journal of Economic Dynamics and Control, 20, 1115-1143.

Hoover, Kevin and Perez, Steven, (1994), "Post Hoc Ergo Propter Hoc one more: an evaluation of 'Does Monetary Policy Matter' in the spirit of James Tobin”, Journal of Monetary Economics, vol. 34, 89-99.

Imbens, Guido and Angrist, Joshua (1994), "Identification and estimation of local average treatment effects”, Econometrica 62, 467-475.

Jones, Ben and Olken, Ben (2005), "Do Leaders Matter? National Leadership and Growth since World War II”, Quarterly Journal of Economics, 120(3), 835-864.

Jurado, K, Ludvigson, S. and Ng, Serena (2013), “Measuring Uncertainty”, NBER WP19456.

Kehrig, M. (2010): “The Cyclicality of Productivity Dispersion”, mimeo Texas University.

Kjetil Storesletten, Christopher I. Telmer, and Amir Yaron. (2005): "Consumption and risk sharing over the life cycle" Journal of Monetary Economics 52, 1331-1358.

Koren, M. and Tenreyro, S. (2007), "Volatility and development", Quarterly Journal of Economics, pp. 243-287.

Kocherlakota, N. (2009): "Some thoughts on the state of macro”, Minneapolis Fed mimeo.

Meghir, C., and L. Pistaferri. (2004): "Income Variance Dynamics and Heterogeneity," Econometrica, 72, 1-32.

Narita, F. (2011): "Hidden Actions, Risk-Taking and Uncertainty Shocks”, mimeo University of Minnesota.

Oi, Walter (1961), “The desirability of price stability under perfect competition”, Econometrica vol 29(1), pp. 58-64.

Popescu, A. and F. Smets (2009). “Uncertainty, Risk-Taking and the Business Cycle”, mimeo.

Ramey, G., and V. Ramey, (1996) "Cross-country evidence on the link between volatility and growth,” American Economic Review, LXXXV (1995), 1138-51.

Schwert, G. W. (1989): "Why Does Stock Market Volatility Change Over Time?” Journal of Finance 44, 1115-1153.

Shiller, R. (1987), “The volatility of stock market prices”, Science, volume 235, pp. 33-37.

Sim, J. (2008): “Uncertainty, Irreversible Investment and General Equilibrium,” Mimeo, Boston University.

Van Nieuwerburgh, Stijn and Veldkamp, Laura (2006), "Learning asymmetries in real business cycles” Journal of Monetary Economics, v53(4), p753-772. 
Zussman, Assaf and Zussman, Noam and Nielsen, Morten (2008): “Asset Market Perspectives on the Israeli-Palestinian Conflict” Economica 75, 84-115. 


\section{APPENDIX}

\section{A1) Data Cleaning:}

Data on GDP growth, stock volatility, stock returns, and exchange rate volatility is windsorized at a $0.1 \%$ level. That is, the lowest and highest $0.1 \%$ of values are constrained to be equal to the $0.1^{\text {th }}$ percentile and $99.9^{\text {th }}$ percentile, respectively. This is done to prevent extreme outliers from driving the results. Censoring the data (dropping the top and bottom $0.1 \%$ ) yields similar results.

We also drop data when the stock market has been suspended for the quarter or data is missing. This affects 4 quarters of data in Mexico, Morocco, Saudi Arabia, and Pakistan. Additionally, we do not use values of 0 for exchange rate volatility, which affects 548 quarters due to fixed exchange rates.

For the purposes of this project, shocks occurring in Hong Kong are considered to occur in China. Shocks occurring in Taiwan are considered separately and as a different country.

Shocks of each type are limited to one per quarter. This impacts 5 quarters for terrorism shocks, 186 quarters for natural disaster shocks, and 1 quarter for political coup shocks. In addition, despite being included in the Center for Research on the Epidemiology of Disasters list of disasters, disease-based disasters, insect-based disasters, and industrial accidents are excluded from the sample.

Bond yields are daily 10-year government bond yields at the close of the day. Exchange rates are the exchange rate at the close of the day relative to the US Dollar. US exchange rate measured against a trade-weighted basket of currencies.

\section{A2) Google News Archive Searches}

Google News' result algorithm produces articles in order of relevance and media outlet importance, so our results comprise a 31 day index of attention focused on the country from the international media. Media is largely English and US-based, driven by both the universe of Google News articles being from US papers with an online presence as well as the fact that the search terms are the English-language names of each country. Overall, Google News categorizes more than 4,500 news sources. For shocks in the United States, state names are used for news attention jump size instead of simply the country name. Blogs and other solely online news sources are excluded from the search.

Google generally caps the number of citations at 100 per search request, but delivers these in order of importance - that is first reporting mentions in the New York Times, Wall Street Journal and other national news before reporting them in local news. Hence, our search results represent the distribution of the new reports focused in particular in the national media around the event. 
Table A1: Economic variables cannot forecast disasters

\begin{tabular}{|c|c|c|c|c|c|c|c|c|}
\hline & (1) & (2) & (3) & (4) & (5) & (6) & (7) & (8) \\
\hline $\begin{array}{l}\text { Shock type as } \\
\text { dependent variable: }\end{array}$ & Natural & Political & Revolution & Terrorist & Natural & Political & Revolution & Terrorist \\
\hline $\begin{array}{l}\text { Level of stock returns, } \\
\text { last quarter }\end{array}$ & $\begin{array}{l}-0.026 \\
(0.026)\end{array}$ & $\begin{array}{c}0.044 \\
(0.037)\end{array}$ & $\begin{array}{l}-0.0003 \\
(0.0006)\end{array}$ & $\begin{array}{c}0.006 \\
(0.014)\end{array}$ & & & & \\
\hline $\begin{array}{l}\text { Volatility of stock } \\
\text { returns, last quarter }\end{array}$ & $\begin{array}{c}0.00001 \\
(0.006)\end{array}$ & $\begin{array}{c}0.009 \\
(0.009)\end{array}$ & $\begin{array}{c}0.002 \\
(0.002)\end{array}$ & $\begin{array}{l}0.0005 \\
(0.003)\end{array}$ & & & & \\
\hline $\begin{array}{l}\text { GDP growth, last } \\
\text { quarter }\end{array}$ & $\begin{array}{l}-0.0007 \\
(0.0004)\end{array}$ & $\begin{array}{c}0.0001 \\
(0.0001)\end{array}$ & $\begin{array}{l}-0.0001 \\
(0.0001)\end{array}$ & $\begin{array}{l}-0.001 \\
(0.001)\end{array}$ & & & & \\
\hline $\begin{array}{l}\text { Volatility of stock } \\
\text { returns, last year }\end{array}$ & & & & & $\begin{array}{c}0.006 \\
(0.009)\end{array}$ & $\begin{array}{c}0.006 \\
(0.009)\end{array}$ & $\begin{array}{c}0.002 \\
(0.002)\end{array}$ & $\begin{array}{l}-0.006 \\
(0.005)\end{array}$ \\
\hline $\begin{array}{l}\text { Level of stock returns, } \\
\text { last year }\end{array}$ & & & & & $\begin{array}{l}-0.029 \\
(0.045)\end{array}$ & $\begin{array}{l}-0.029 \\
(0.045)\end{array}$ & $\begin{array}{l}-0.008 \\
(0.008)\end{array}$ & $\begin{array}{l}-0.011 \\
(0.012)\end{array}$ \\
\hline GDP growth, last year & & & & & $\begin{array}{c}-0.001 \\
(0.0007)\end{array}$ & $\begin{array}{l}-0.001 \\
(0.001)\end{array}$ & $\begin{array}{l}-0.0001 \\
(0.0001)\end{array}$ & $\begin{array}{c}-0.001 \\
(0.0007)\end{array}$ \\
\hline F-test p-value & 0.154 & 0.486 & 0.808 & 0.832 & 0.396 & 0.462 & 0.776 & 0.452 \\
\hline Observations & 5643 & 5643 & 5643 & 5643 & 6355 & 6355 & 6355 & 6355 \\
\hline
\end{tabular}

Notes: * significant at 10\%; ** significant at 5\%; *** significant at 1\%. All columns are estimated in OLS with standard-errors clustered at the country level, and all shocks weighted by their increase in media coverage. Data is quarterly by country from 1970 until 2013 . All columns include a full set of country dummies and year by quarter dummies. The F-test p-value is the probability value of the F-test of the three economic variables in each column. 
Table A2: Correlations of Different Volatility Measures

(1) (2)

Specification

Stock Volatility

Cross-Firm Volatility

1.00

Stock Volatility

1.00

Cross-Firm Volatility

Bond Yield Volatility

Exchange Rate Volatility
(3)

Bond Yield Volatility
(4)

Exchange Rate Volatility

$0.1343^{* * *}$

$0.1670 * * *$

$0.0921 * * *$

$0.1837 * * *$

$-0.1064 * * *$

$-0.0899 * * *$

1.00

Notes: * significant at 10\%; ** significant at 5\%; *** significant at 1\%. Data is quarterly by country from 1970 until 2013. Table gives pairwise correlations of four measures of volatility. Italicized numbers give pairwise correlations of the measures after being demeaned by country and time. 
Table 1: Simulation data - estimated impact of returns and volatility on GDP Growth

\begin{tabular}{|c|c|c|c|c|c|}
\hline & (1) & (2) & (3) & (4) & (5) \\
\hline Estimation procedure & OLS & OLS & IV & IV & IV \\
\hline Period: & Quarterly & Yearly & Quarterly & Yearly & Yearly \\
\hline Level of returns $\mathrm{t}_{\mathrm{t}-1}$ & $\begin{array}{c}0.149 * * * \\
(0.007)\end{array}$ & $\begin{array}{c}0.237 * * * \\
(0.014)\end{array}$ & $\begin{array}{c}0.312 * * \\
(0.133)\end{array}$ & $\begin{array}{c}0.611^{* *} \\
(0.339)\end{array}$ & $\begin{array}{c}0.683^{* * *} \\
(0.030)\end{array}$ \\
\hline Volatility of returns $\mathrm{t}_{\mathrm{t}-1}$ & $\begin{array}{c}-0.052 \\
(0.013)\end{array}$ & $\begin{array}{c}-0.114^{* * *} \\
(0.023)\end{array}$ & $\begin{array}{l}-0.127 \\
(0.127)\end{array}$ & $\begin{array}{c}-0.230 * * \\
(0.113)\end{array}$ & $\begin{array}{c}-0.306^{* * *} \\
(0.038)\end{array}$ \\
\hline & & & \multicolumn{3}{|c|}{ IV $1^{\text {st }}$ stage: Level (of Stock Returns) } \\
\hline Natural Disasters $_{t-1}$ & & & $-0.045^{* * *}$ & $-0.045^{* * *}$ & \\
\hline Political Shocks $_{\mathrm{t}-1}$ & & & $0.059 * * *$ & $0.123 * * *$ & \\
\hline Revolutions $_{\mathrm{t}-1}$ & & & $-0.193 * * *$ & -0.053 & \\
\hline Terrorist attacks $_{\mathrm{t}-1}$ & & & $-0.108 * * *$ & -0.005 & \\
\hline Shock $_{\mathrm{t}-1}$ & & & & & $0.771 * * *$ \\
\hline Variance $_{t-1}$ & & & & & $0.656 * * *$ \\
\hline Instrument F-test & & & 71.40 & 20.90 & 7346 \\
\hline & & & \multicolumn{3}{|c|}{ IV $1^{\text {st }}$ stage: Volatility (of Stock Returns) } \\
\hline Natural Disasters $_{t-1}$ & & & 0.009 & 0.001 & \\
\hline Political Shocks $_{\mathrm{t}-1}$ & & & $0.123 * * *$ & $0.412^{* * *}$ & \\
\hline Revolutions $_{\mathrm{t}-1}$ & & & $0.324 * * *$ & $0.638 * * *$ & \\
\hline Terrorist attacks $_{\mathrm{t}-1}$ & & & $0.154^{* * *}$ & $0.433 * * *$ & \\
\hline Shock $_{\mathrm{t}-1}$ & & & & & $-0.063 * * *$ \\
\hline Variance $_{t-1}$ & & & & & $2.72 * * *$ \\
\hline Instrument F-test & & & 73.42 & 380.33 & 11792 \\
\hline Sargan test p-value & & & 0.761 & 0.748 & $\mathrm{n} / \mathrm{a}$ \\
\hline Observations & 7140 & 6900 & 7140 & 6900 & 6900 \\
\hline Year-Quarter dummies & Yes & Yes & Yes & Yes & Yes \\
\hline
\end{tabular}

Notes: The dependent variable is simulated GDP growth. * significant at $10 \%$; ** significant at $5 \%$; *** significant at $1 \%$. All regressions have GDP growth as the dependent variable, with standard errors clustered at the country level. The underlying simulation sample is 30 years of quarters data on 6,000 countries, but to generate standard errors consistent with our empirical sample of 60 countries we block bootstrap over countries 1000 times with replacement. Quarterly GDP growth is current versus last quarter growth. Yearly GDP growth is current versus four quarters growth. Annual stock returns are averaged over last year, and annual volatility is calculated over the last year. Sargan test is the test of the over-identification restrictions. 
Table 2: Descriptive Statistics (yearly frequency)

\begin{tabular}{lcccccc}
\hline \hline & Obs. & Mean & Median & Std. Dev. & Min & Max \\
\hline Annual GDP Growth, \% & 8942 & 3.71 & 3.54 & 5.23 & -26.32 & 42.37 \\
Stock Returns, \% & 6410 & 1.00 & 1.39 & 8.11 & -46.5 & 42.0 \\
Log (Stock Ret. Volatility) & 6408 & -4.49 & -4.51 & .469 & -6.06 & -2.52 \\
Cross Sectional Returns & 4099 & -.001 & .001 & .09 & -.38 & .93 \\
Log ( Cross Sectional Volatility) & 4059 & -1.59 & -1.58 & .32 & -3.47 & -.626 \\
Bond Yields, \% & 4566 & 8.48 & 7.46 & 6.79 & 1.07 & 208.2 \\
Log (Bond Yield Volatility) & 4486 & -4.49 & -4.56 & .879 & -11.23 & -1.42 \\
Log (Exchange Rates, per \$) & 8204 & 1.55 & 0.94 & 2.70 & -7.96 & 10.12 \\
Log(Exch. Rate Volatility) & 7797 & -0.83 & -.585 & 1.03 & -7.64 & 2.39 \\
Natural Disasters & 8942 & .388 & 0 & .688 & 0 & 4 \\
Natural Disasters (scaled by media increase) & 8942 & .147 & 0 & .502 & 0 & 7.98 \\
Political Shocks & 8942 & .010 & 0 & .099 & 0 & 1 \\
Political Shocks (scaled by media increase) & 8942 & .026 & 0 & .396 & 0 & 14.07 \\
Revolution shock & 8942 & .004 & 0 & .063 & 0 & 1 \\
Revolutions (scaled by media increase) & 8942 & .004 & 0 & .062 & 0 & 2.47 \\
Terrorist attacks & 8942 & .016 & 0 & .163 & 0 & 1 \\
Terrorist attacks (scaled by media increase) & 8942 & .019 & 0 & .280 & 0 & 10.10 \\
GDP Per Capita (2005 \$US, World Bank & 8942 & 23,761 & 23,920 & 16,616 & 1335 & 78,559 \\
PPP) & & & & & & \\
\hline
\end{tabular}

Notes: All values are yearly averages unless noted otherwise. Data from 60 countries from 1970 to 2013. 
Table 3: Real data - estimated impact of returns and volatility on GDP Growth

\begin{tabular}{|c|c|c|c|c|c|c|}
\hline & (1) & (2) & (3) & (4) & (5) & (6) \\
\hline Estimation & OLS & OLS & IV & IV & IV & IV \\
\hline Period: & Quarterly & Yearly & Quarterly & Yearly & Yearly & Yearly \\
\hline Stock Measure & Index & Index & Index & Index & Cross Sect & PCF \\
\hline Level of returns $t_{t-1}$ & $\begin{array}{c}1.047 * * * \\
(0.252)\end{array}$ & $\begin{array}{c}8.890 * * * \\
(1.138)\end{array}$ & $\begin{array}{c}10.304 * * * \\
(3.869)\end{array}$ & $\begin{array}{c}25.867 * * * \\
(7.583)\end{array}$ & $\begin{array}{c}31.654 \\
(22.709)\end{array}$ & $\begin{array}{c}2.351^{* * *} \\
(0.505)\end{array}$ \\
\hline $\begin{array}{l}\text { Volatility of returns } \mathrm{t}_{\mathrm{t}-1} \\
\text { (in logs) }\end{array}$ & $\begin{array}{c}-0.257 * * * \\
(0.085)\end{array}$ & $\begin{array}{c}-0.842^{* *} \\
(0.411)\end{array}$ & $\begin{array}{c}-2.873 * * * \\
(0.893)\end{array}$ & $\begin{array}{c}-14.183^{* * *} \\
(2.243)\end{array}$ & $\begin{array}{c}-21.134 * * \\
(9.086)\end{array}$ & $\begin{array}{c}-7.768 * * * \\
(0.808)\end{array}$ \\
\hline $\begin{array}{l}\text { Magnitudes: } \\
\text { Level Coeff } \times \text { SD level } \\
\text { Vol Coeff } \times \text { SD vol }\end{array}$ & $\begin{array}{r}0.16 \\
-0.15\end{array}$ & $\begin{array}{r}0.76 \\
-0.42\end{array}$ & $\begin{array}{c}1.61 \\
-1.64\end{array}$ & $\begin{array}{l}2.20 \\
-7.11\end{array}$ & $\begin{array}{r}3.16 \\
-6.83\end{array}$ & $\begin{array}{l}2.35 \\
-7.77\end{array}$ \\
\hline IV $1^{\text {st }}$ stage: & & & & Level (of Stc & $\mathrm{k}$ Returns $\mathrm{t}_{\mathrm{t}-1}$ & \\
\hline Natural Disasters $_{\mathrm{t}-1}$ & & & $\begin{array}{l}-0.0147 \\
(0.0203)\end{array}$ & $\begin{array}{l}-0.014 \\
(0.015)\end{array}$ & $\begin{array}{l}-0.019 \\
(0.018)\end{array}$ & $\begin{array}{l}-0.218^{\dagger} \\
(0.144)\end{array}$ \\
\hline Political Shocks $\mathrm{t}-1$ & & & $\begin{array}{c}0.112^{* * *} \\
(0.022)\end{array}$ & $\begin{array}{c}0.168 * * * \\
(0.024)\end{array}$ & $\begin{array}{c}0.020 \\
(0.070)\end{array}$ & $\begin{array}{c}1.528 * * * \\
(0.498)\end{array}$ \\
\hline Revolutions $_{\mathrm{t}-1}$ & & & $\begin{array}{c}-0.396^{* * *} \\
(0.029)\end{array}$ & $\begin{array}{c}-0.459 * * * \\
(0.034)\end{array}$ & $\begin{array}{c}-0.516^{* * *} \\
(0.035)\end{array}$ & $\begin{array}{c}-6.423 * * * \\
(0.414)\end{array}$ \\
\hline Terrorist attack $\mathrm{t}_{\mathrm{t}-1}$ & & & $\begin{array}{c}-0.021^{* * *} \\
(0.007)\end{array}$ & $\begin{array}{l}-0.010^{*} \\
(0.006)\end{array}$ & $\begin{array}{c}-0.019 * * * \\
(0.005)\end{array}$ & $\begin{array}{c}-0.185 * * * \\
(0.053)\end{array}$ \\
\hline Instrument F-test & & & 65.99 & 54.33 & 65.36 & 85.83 \\
\hline IV $1^{\text {st }}$ stage: & & & \multicolumn{4}{|c|}{ Volatility (of Stock Returns $\mathrm{t}_{\mathrm{t}-1}$ ) } \\
\hline Natural Disasters ${ }_{t-1}$ & & & $\begin{array}{c}0.101 \\
(0.089)\end{array}$ & $\begin{array}{c}0.041 \\
(0.084)\end{array}$ & $\begin{array}{c}0.022 \\
(0.049)\end{array}$ & $\begin{array}{l}-0.0674 \\
(0.152)\end{array}$ \\
\hline Political Shocks $\mathrm{t}_{-1}$ & & & $\begin{array}{c}0.531 * * * \\
(0.125)\end{array}$ & $\begin{array}{c}0.450 * * * \\
(0.149)\end{array}$ & $\begin{array}{c}0.192 * * * \\
(0.042)\end{array}$ & $\begin{array}{c}1.052 * * * \\
(0.227)\end{array}$ \\
\hline Revolutions $_{\mathrm{t}-1}$ & & & $\begin{array}{c}1.052^{* * *} \\
(0.136)\end{array}$ & $\begin{array}{c}1.990 * * * \\
(0.132)\end{array}$ & $\begin{array}{c}1.285^{* * *} \\
(0.090)\end{array}$ & $\begin{array}{c}4.065^{* * *} \\
(0.258)\end{array}$ \\
\hline Terrorist attacks $\mathrm{t}-1$ & & & $\begin{array}{r}-0.0412 \\
(0.029)\end{array}$ & $\begin{array}{l}-0.048 \\
(0.049)\end{array}$ & $\begin{array}{l}0.045 * * \\
(0.022)\end{array}$ & $\begin{array}{l}0.087^{*} \\
(0.045)\end{array}$ \\
\hline Instrument F-test & & & 18.92 & 59.09 & 57.71 & 77.69 \\
\hline Sargan test p-value & & & 0.131 & 0.342 & 0.339 & 0.796 \\
\hline Observations & 5671 & 6365 & 5647 & 6365 & 4060 & 4004 \\
\hline Countries & 58 & 60 & 58 & 60 & 42 & 42 \\
\hline $\begin{array}{l}\text { Year-Quarter } \\
\text { dummies }\end{array}$ & Yes & Yes & Yes & Yes & Yes & Yes \\
\hline
\end{tabular}

Notes: The dependent variable is GDP growth. ${ }^{\dagger}$ significant at the $15 \%$ level, * significant at $10 \%$; ${ }^{* *}$ significant at 5\%; *** significant at 1\%. Standard errors clustered by country. Data is quarterly by country from 1970 until 2013. Columns (1) to (2) estimated by OLS and (4) to (6) by instrumental variables. Instruments are scaled by the increase in media mentions of the country in the 15-days after the shock compared to the 15-days before the shock. Sargan test is the over-identification test of instrument validity. All columns include a full set of country dummies and a full set of year by quarter dummies. 
Table 4: Real data - estimated impact of higher moments on GDP Growth

\begin{tabular}{|c|c|c|c|c|c|c|}
\hline $\begin{array}{l}\text { Estimation } \\
\text { Period: }\end{array}$ & $\begin{array}{c}\mathbf{( 1 )} \\
\text { OLS } \\
\text { Yearly }\end{array}$ & $\begin{array}{c}(2) \\
\text { IV } \\
\text { Yearly }\end{array}$ & $\begin{array}{c}(3) \\
\text { IV } \\
\text { Yearly }\end{array}$ & $\begin{array}{c}\mathbf{( 4 )} \\
\text { OLS } \\
\text { Yearly }\end{array}$ & $\begin{array}{c}\mathbf{( 5 )} \\
\text { IV } \\
\text { Yearly }\end{array}$ & $\begin{array}{c}\mathbf{( 6 )} \\
\text { IV } \\
\text { Yearly }\end{array}$ \\
\hline Stock Measure & Index & Index & Index & Cross Sect & Cross Sect & Cross Sect \\
\hline Level of returns $_{t-1}$ & $\begin{array}{c}8.846^{* * *} \\
(1.148)\end{array}$ & $\begin{array}{c}18.90 \\
(57.15)\end{array}$ & & $\begin{array}{c}5.501 * * * \\
(1.585)\end{array}$ & $\begin{array}{l}37.17^{*} \\
(20.47)\end{array}$ & \\
\hline $\begin{array}{l}\text { Volatility of returns } \mathrm{t}_{-1} \\
\text { (in logs) }\end{array}$ & $\begin{array}{c}-0.830 * * \\
(0.417)\end{array}$ & $\begin{array}{l}-16.833 \\
(16.413)\end{array}$ & & $\begin{array}{c}-2.358 * * * \\
(0.552)\end{array}$ & $\begin{array}{c}-20.84 * * \\
(9.470)\end{array}$ & \\
\hline Skewness of returns $\mathrm{t}_{\mathrm{t}-1}$ & $\begin{array}{c}-0.568^{* *} \\
(0.246)\end{array}$ & $\begin{array}{l}-22.806 \\
(57.31)\end{array}$ & $\begin{array}{l}-1.433 \\
(24.26)\end{array}$ & $\begin{array}{c}0.221 \\
(0.159)\end{array}$ & $\begin{array}{l}-2.668 \\
(3.726)\end{array}$ & $\begin{array}{c}4.393 \\
(7.724)\end{array}$ \\
\hline $\begin{array}{l}\text { Kurtosis of returns } \mathrm{t}_{\mathrm{t}-1} \\
\text { (in logs) }\end{array}$ & $\begin{array}{c}0.120 \\
(0.496)\end{array}$ & $\begin{array}{c}23.66 \\
(144.15)\end{array}$ & $\begin{array}{l}-32.076 \\
(52.376)\end{array}$ & $\begin{array}{c}0.463^{* *} \\
(0.227)\end{array}$ & $\begin{array}{c}3.545 \\
(4.780)\end{array}$ & $\begin{array}{c}4.923 \\
(11.890)\end{array}$ \\
\hline $\begin{array}{l}\text { Magnitudes: } \\
\text { Level Coeff } \times \text { SD level } \\
\text { Vol Coeff } \times \text { SD vol }\end{array}$ & $\begin{array}{r}0.75 \\
-0.42 \\
\end{array}$ & $\begin{array}{r}1.61 \\
-8.44 \\
\end{array}$ & & $\begin{array}{r}0.548 \\
-0.763 \\
\end{array}$ & $\begin{array}{r}3.71 \\
-6.74 \\
\end{array}$ & \\
\hline IV $1^{\text {st }}$ stage: & & & evel (of 5 & k Returns $\mathrm{t}_{\mathrm{t}-1}$ & & \\
\hline Natural Disasters ${ }_{t-1}$ & & $\begin{array}{c}-0.014 \\
(0.015)\end{array}$ & & & $\begin{array}{l}-0.019 \\
(0.018)\end{array}$ & \\
\hline Political Shocks $_{\mathrm{t}-1}$ & & $\begin{array}{c}0.168^{* * *} \\
(0.024)\end{array}$ & & & $\begin{array}{c}0.020 \\
(0.070)\end{array}$ & \\
\hline Revolutions $_{\mathrm{t}-1}$ & & $\begin{array}{c}-0.459 * * * \\
(0.034)\end{array}$ & & & $\begin{array}{c}-0.516^{* * * *} \\
(0.035)\end{array}$ & \\
\hline Terrorist attack $\mathrm{t}_{\mathrm{t} 1}$ & & $\begin{array}{l}-0.010^{*} \\
(0.006)\end{array}$ & & & $\begin{array}{c}-0.019 * * * \\
(0.005)\end{array}$ & \\
\hline Instrument F-test & & 54.33 & & & 65.36 & \\
\hline IV $1^{\text {st }}$ stage: & \multicolumn{6}{|c|}{ Volatility (of Stock Returns $\mathrm{t}_{\mathrm{t}-1}$ ) } \\
\hline Natural Disasters $\mathrm{t}_{-1}$ & & $\begin{array}{c}0.041 \\
(0.084)\end{array}$ & & & $\begin{array}{c}0.022 \\
(0.049)\end{array}$ & \\
\hline Political Shocks $\mathrm{t}_{\mathrm{t}-1}$ & & $\begin{array}{c}0.450 * * * \\
(0.149)\end{array}$ & & & $\begin{array}{c}0.192 * * * \\
(0.042)\end{array}$ & \\
\hline Revolutions $_{\mathrm{t}-1}$ & & $\begin{array}{c}1.990 * * * \\
(0.132)\end{array}$ & & & $\begin{array}{c}1.285^{* * * *} \\
(0.090)\end{array}$ & \\
\hline Terrorist attacks $\mathrm{t}_{\mathrm{t}-1}$ & & $\begin{array}{l}-0.048 \\
(0.049)\end{array}$ & & & $\begin{array}{c}0.045^{* *} \\
(0.022)\end{array}$ & \\
\hline Instrument F-test & & 59.09 & & & 57.71 & \\
\hline Sargan test p-value & & & 0.552 & & & 0.166 \\
\hline $\begin{array}{l}\text { Observations } \\
\text { Countries }\end{array}$ & $\begin{array}{c}6365 \\
60\end{array}$ & $\begin{array}{c}6365 \\
60\end{array}$ & $\begin{array}{c}6365 \\
60\end{array}$ & $\begin{array}{c}4060 \\
42\end{array}$ & $\begin{array}{c}4060 \\
42\end{array}$ & $\begin{array}{c}4060 \\
42\end{array}$ \\
\hline $\begin{array}{l}\text { Year-Quarter } \\
\text { dummies }\end{array}$ & Yes & Yes & Yes & Yes & Yes & Yes \\
\hline
\end{tabular}

Notes: The dependent variable is GDP growth. * significant at 10\%; ** significant at 5\%; *** significant at $1 \%$. Standard errors clustered by country. Data is quarterly by country from 1970 until 2013. Instruments are scaled by the increase in media mentions of the country in the 15-days after the shock compared to the 15-days before the shock. Sargan test is the over-identification test of instrument validity. All columns include a full set of country dummies and a full set of year by quarter dummies. For parsimony the first stage for Skewness and Kurtosis of stock returns has not been shown (the F-test was 3.53, 2.52 respectively in columns 2, 3; and 4.64, 9.18 in columns 5, 6). Volatility and Kurtosis are in logs, while returns and skewness are in levels because they contain negative values. 
Table 5: Alternate Measures of $1^{\text {st }}$ and $2^{\text {nd }}$ Moment Shocks

\begin{tabular}{|c|c|c|c|c|c|}
\hline Specification & $\begin{array}{c}\text { (1) } \\
\text { Baseline stock } \\
\text { index returns }\end{array}$ & $\begin{array}{c}\text { (2) } \\
\text { Cross-Firm } \\
\text { stock returns }\end{array}$ & $\begin{array}{c}\text { (3) } \\
\text { Sovereign } \\
\text { Bond Yields }\end{array}$ & $\begin{array}{c}\text { (4) } \\
\text { Exchange Rates } \\
\text { Returns }\end{array}$ & $\begin{array}{l}\mathbf{( 5 )} \\
\text { Forecaster mean } \\
\text { and spread }\end{array}$ \\
\hline Level of stock returns ${ }_{t-1}$ & $\begin{array}{l}25.867 * * * \\
(7.583)\end{array}$ & & & & \\
\hline Volatility of stock returns $\mathrm{t}_{\mathrm{t}-1}$ (in logs) & $\begin{array}{c}-14.183^{* * *} \\
(2.243)\end{array}$ & & & & \\
\hline Level of cross-firm stock returns ${ }_{t-1}$ & & $\begin{array}{c}31.654 \\
(22.709)\end{array}$ & & & \\
\hline Volatility of cross-firm stock returns $\mathrm{t}_{\mathrm{t}-1}$ (in logs) & & $\begin{array}{l}-21.134^{* *} \\
(9.086)\end{array}$ & & & \\
\hline Level of bond yields $s_{t-1}$ & & & $\begin{array}{c}0.899 * * * \\
(0.153)\end{array}$ & & \\
\hline Volatility of bond yields $\mathrm{t}_{\mathrm{t}-1}$ (in logs) & & & $\begin{array}{l}-3.54^{* *} \\
(1.407)\end{array}$ & & \\
\hline Level of currency returns ${ }_{t-1}$ & & & & $\begin{array}{c}55.64 * * \\
(28.07)\end{array}$ & \\
\hline Volatility of currency returns t-1 $_{\text {(in logs) }}$ & & & & $\begin{array}{c}-6.127 * * * \\
(2.132)\end{array}$ & \\
\hline Level of GDP forecasts (mean, in levels) & & & & & $\begin{array}{c}0.136 \\
(1.317)\end{array}$ \\
\hline Disagreement of GDP forecasts (span, in logs) & & & & & $\begin{array}{c}-13.685^{* *} \\
(6.797) \\
\end{array}$ \\
\hline $\begin{array}{l}\text { Relative Magnitude } \\
{[\text { vol coeff } \times \text { SD vol]/[level coeff } \times \text { SD level] }}\end{array}$ & 3.23 & 2.17 & 0.638 & 0.481 & 20.61 \\
\hline IV F-tests (level and vol) & 54.33 & 65.36 & 200.5 & 3.07 & 65.49 \\
\hline Sargan p-value & $\begin{array}{l}59.09 \\
0.342\end{array}$ & $\begin{array}{l}57.71 \\
0.339\end{array}$ & $\begin{array}{c}8.30 \\
0.277\end{array}$ & $\begin{array}{c}4.37 \\
0.855\end{array}$ & $\begin{array}{l}37.86 \\
0.545\end{array}$ \\
\hline $\begin{array}{l}\text { Observations } \\
\text { Countries }\end{array}$ & $\begin{array}{c}6365 \\
60\end{array}$ & $\begin{array}{c}4060 \\
42\end{array}$ & $\begin{array}{c}4490 \\
43\end{array}$ & $\begin{array}{c}6607 \\
56\end{array}$ & $\begin{array}{c}1695 \\
23\end{array}$ \\
\hline
\end{tabular}

60

Notes: The dependent variable is GDP growth. ${ }^{\dagger}$ significant at $15 \%$, * significant at $10 \%$; ** significant at $5 \%$; *** significant at $1 \%$. Standard errors clustered by country. Data is quarterly by country from 1970 until 2013. Instruments are all multiplied by the increase in media mentions of the country in the 15-days after the shock compared to the 15-days before the shock. All columns include a full set of country dummies and year by quarter dummies. Volatility is in logs in the regression. 
Table 6: Robustness of Main Stock Returns Results to Alternate Specifications and Sample Splits

\begin{tabular}{|c|c|c|c|c|c|c|c|}
\hline Specification & $\begin{array}{c}\text { (1) } \\
\text { Baseline }\end{array}$ & $\begin{array}{c}\text { (2) } \\
\text { No scaling by } \\
\text { media coverage }\end{array}$ & $\begin{array}{c}\text { (3) } \\
\text { Population } \\
\text { weighted }\end{array}$ & $\begin{array}{c}\mathbf{( 4 )} \\
\text { No natural } \\
\text { disaster IV }\end{array}$ & $\begin{array}{c}\text { (5) } \\
\text { Split by GDP per } \\
\text { capita }\end{array}$ & $\begin{array}{c}\mathbf{( 6 )} \\
\text { Split by } \\
\text { population } \\
\text { size } \\
\end{array}$ & $\begin{array}{c}\mathbf{( 7 )} \\
\text { Split by } \\
\text { time } \\
\text { period }\end{array}$ \\
\hline Level of returns ${ }_{t-1}$ & $\begin{array}{c}25.867 * * * \\
(7.583)\end{array}$ & $\begin{array}{c}31.509 * * * \\
(9.970)\end{array}$ & $\begin{array}{c}24.534 * * * \\
(8.016)\end{array}$ & $\begin{array}{c}28.820 * * * \\
(7.183)\end{array}$ & $\begin{array}{c}6.640 \\
(21.153)\end{array}$ & $\begin{array}{c}66.781 \\
(44.793)\end{array}$ & $\begin{array}{l}22.716^{* * * *} \\
(8.830)\end{array}$ \\
\hline $\begin{array}{l}\text { Volatility of returns } \mathrm{t}_{\mathrm{t}-1} \\
\text { (in logs) }\end{array}$ & $\begin{array}{l}-14.183 * * * \\
(2.243)\end{array}$ & $\begin{array}{c}-13.146 * * * \\
(3.105)\end{array}$ & $\begin{array}{c}-14.780 * * * \\
(2.209)\end{array}$ & $\begin{array}{c}-14.886 * * * \\
(1.933)\end{array}$ & $\begin{array}{l}-13.294 * * * \\
(2.471)\end{array}$ & $\begin{array}{c}-13.939 * * * \\
(5.944)\end{array}$ & $\begin{array}{c}-13.793 * * * \\
(4.126)\end{array}$ \\
\hline Rich*Level of returns ${ }_{t-1}$ & & & & & $\begin{array}{c}-4.668 \\
(25.185)\end{array}$ & & \\
\hline Rich*$^{*}$ Volatility of returns $\mathrm{t}_{\mathrm{t}-1}$ & & & & & $\begin{array}{c}21.215 \\
(12.854)\end{array}$ & & \\
\hline Big* Level of returns $_{t-1}$ & & & & & & $\begin{array}{l}-50.710 \\
(51.025)\end{array}$ & \\
\hline Big*Volatility of returns $_{\mathrm{t}-1}$ & & & & & & $\begin{array}{l}-2.415 \\
(3.139)\end{array}$ & \\
\hline Post $2000 *$ Level of returns $_{t-1}$ & & & & & & & $\begin{array}{c}-4.263 \\
(47.253)\end{array}$ \\
\hline Post2000*Vol of returns $_{\mathrm{t}-1}$ & & & & & & & $\begin{array}{c}-7.422 \\
(13.546) \\
\end{array}$ \\
\hline \multicolumn{8}{|l|}{ Relative Magnitude } \\
\hline \multirow{2}{*}{ IV F-tests (level and vol) } & 54.33 & 52.91 & 49.10 & 71.18 & 121.02 & 228.07 & 95.20 \\
\hline & 59.09 & 58.14 & 53.61 & 78.76 & 38.26 & 93.41 & 53.32 \\
\hline Sargan p-value & 0.342 & 0.366 & 0.427 & 0.340 & 0.273 & 0.599 & 0.220 \\
\hline Observations & 6365 & 6365 & 6365 & 6365 & 6365 & 6365 & 6365 \\
\hline
\end{tabular}

Notes: The dependent variable is GDP growth. * significant at $10 \%$; ** significant at $5 \%$; *** significant at $1 \%$. Standard errors clustered by country. Data is quarterly by country from 1970 until 2013. All columns estimated by instrumental variables with a full set of quarter-by-year time dummies. Instruments are all multiplied by the increase in media mentions of the country in the 15-days after the shock compared to the 15-days before the shock, except for column (2) which is not multiplied at all (but the instruments are only used for jumps of $25 \%$ or more). All columns include a full set of country dummies and year by quarter dummies. Volatility is in logs in the regression. The split by GDP per capita in column (5) splits countries by the sample median of long-run GDP per capita, which is \$25,000 (in 2010 dollars). The split in column (6) is by whether countries have more than 25m population (the sample median) in 2009. The split in column (7) is by the time period being pre-2000 or greater than equal to 2000. 